\title{
A escolha do periódico científico sob a perspectiva financeira: análise do estrato $A 1$ na área 21
}

Moisés Vieira de Carvalho ${ }^{\mathrm{a},{ }^{\circledR}}$; Juliana Bohnen Guimarães ${ }^{\mathrm{a}}$; Camila Cristina Fonseca Bicalho $^{\mathrm{a}(\mathrm{C}}$, Thaíze Cristina Diniz da Silva ${ }^{a}$; Avner Henrique Del Peloso de Brito ${ }^{\circledR}$; Frederico Sander Mansur Machado ${ }^{\text {b,c }}$; Cândido Celso Coimbrac(i)

\section{Palavras Chave:}

Fator de impacto de periódicos;

Custo;

Publicação;

Qualis/Capes.

\section{Keywords:}

Journal Impact Factor;

Costs;

Publication;

Qualis/Capes.

\begin{abstract}
RESUMO
O objetivo do estudo foi classificar as revistas A1, área 21, de acordo com as taxas envolvidas no processo de publicação. Os periódicos foram selecionados a partir da área Educação Física, quadriênio 2013-2016. A busca foi realizada em Abril de 2019. As informações referentes ao custeio incluíram taxas de submissão, processamento e/ou tramitação, publicação e cobranças adicionais. As despesas com o acesso aberto também foram atribuídas aos autores. Os periódicos foram classificados dos mais baratos para os mais caros. Em caso de igualdade nos valores cobrados, utilizou-se o fator de impacto como critério de desempate, seguindo a ordem decrescente para esse índice. Dos 235 periódicos, somente 8 apresentaram gratuidade no processo. Considerando o cenário de financiamentos limitados para pesquisa tais achados poderiam impactar na produtividade científica nacional.
\end{abstract}

\section{ABSTRACT}

The objective of this study was to classify the A1 journals of area 21 according to the rates involved in the publication process. The journals were selected from the Physical Education evaluation area, quadrennium 2013-2016. The search was conducted in April 2019. Costing information included submission, processing, publication and additional fees. Open access expenditure has also been allocated. The journals have been ranked from the cheapest to the most expensive. Only 8 of 235 journals presented gratuity in the process. Considering the scenario of limited research funding, such findings could impact on national scientific productivity.

\section{RESUMEN}

El objetivo del estudio fue clasificar las revistas A1, área 21, de acuerdo con las tasas involucradas en el proceso de publicación. Las revistas fueron seleccionadas del área de Educación Física, cuatrienio 2013-2016. La búsqueda se realizó en abril de 2019. La información de costos incluyó el envío, el procesamiento y / o las tarifas de procesamiento, la publicación y los cargos adicionales. Los gastos con acceso abierto también se atribuyeron al autor. Las revistas se clasificaron del más barato al más caro. En caso de igualdad en las cantidades cobradas, el factor de impacto se consideró el desempate, siguiendo el orden descendente de este índice. De las 235 revistas, solo 8 se presentaron de forma gratuita en el proceso. Considerando el escenario de financiamiento limitado para la investigación, tales hallazgos podrían afectar la productividad científica nacional.

\footnotetext{
a Universidade do Estado de Minas Gerais, Unidade Ibirité, Departamento de Ciências do Movimento Humano, Ibirité, MG, Brasil. 'Universidade Estadual de Montes Claros, Departamento de Educação Física, Montes Claros, MG, Brasil.

' Universidade Federal de Minas Gerais, Instituto de Ciências Biológicas, Laboratório de Endocrinologia e Metabolismo, Belo Horizonte, MG, Brasil.
}

Autor correspondente: Moisés Vieira de Carvalho

E-mail: moises.carvalho@uemg.br

Recebido em 18 de Agosto de 2019; Aceito em 23 de Outubro de 2019. 


\section{INTRODUÇÃO}

A ciência se expressa por meio da geração de conhecimento de maneira metódica e reprodutível e possui ainda critérios sistemáticos para a quantificação e qualificação de seus produtos. No Brasil, a supervisão da produção científica dos programas acadêmicos de pós-graduação tem sido feita através do sistema Qualis, desenvolvido pela Coordenação de Aperfeiçoamento de Pessoal de Nível Superior (CAPES). Esse sistema disponibiliza uma lista contendo a classificação dos periódicos em estratos ou níveis categóricos, por área temática, via Plataforma Sucupira (CAPES, 2013).

Esse processo de classificação depende da atuação de comitês consultores das respectivas áreas e considera, dentre outros critérios métricos, o fator de impacto dos periódicos como uma ferramenta indicadora de qualidade das publicações (Ruiz et al., 2009). Reconhecidamente, o fator de impacto dos periódicos utiliza critérios como o número de citações dos artigos; a periodicidade de publicação; o número mínimo de trabalhos em cada exemplar; a língua de veiculação; a área de inserção, editoração e formatação; enfim, elementos que contribuem para a avaliação da produção intelectual (Marques, 2009). Ainda, há de se considerar que o fator de impacto é um critério que possui vinculação a entidade privada, o que pode gerar hegemonias de áreas e grupos, a partir da mercantilização dos produtos acadêmicos e científicos (Zingano, 2017). Embora haja diferentes críticas ao uso do fator de impacto como métrica de avaliação, o sistema tem sido utilizado pelos pesquisadores brasileiros como um referencial para a tomada de decisão quanto ao periódico escolhido visando tanto à obtenção de financiamentos juntos as agências de fomento quanto para divulgação de seus trabalhos científicos.

Contudo, a obtenção de "bons produtos", buscando atender as demandas da lógica produtivista atual, depende também da compreensão dos custos relacionados ao processo de publicação (Bicas e Chamom, 2012). De acordo com Príncipe e Barradas (2013), tais despesas visam garantir a sustentabilidade dos periódicos e envolvem o pagamento de diferentes valores, cobrados sob a forma de taxas, assinaturas ou modos de publicação. Consequentemente, tais custos podem representar um impacto relevante para a produção científica, devendo ser incorporados às propostas de financiamento dos projetos de pesquisa.

Por definição, a taxa de publicação trata-se do valor cobrado pelas revistas para processarem os manuscritos aprovados, subentendendo que as instituições e os autores seriam os maiores beneficiados com a sua publicação e por essa razão deveriam arcar com o ônus. Já a taxa de submissão é compreendida como uma quantia cobrada aos autores pelo envio e avaliação do manuscrito, independentemente do aceite. Essa taxa não tem caráter reembolsável, porém, há ocasiões em que é abatida do valor da taxa de publicação (Príncipe e Barradas, 2013). Além dessas, a taxa de processamento ou tramitação incide sobre os custos da publicação desde seu início. Em geral, muitas revistas cobram o pagamento das taxas de publicação e submissão, assim como, caso haja a necessidade de utilização de ilustrações coloridas e um número de páginas superior às normativas da revista ou editora, há cobrança por adicionais. Por fim, muitas revistas em circulação cobram pelo pagamento de assinaturas (Bicas e Chamom, 2012). Nessa perspectiva, o modelo poderia ser custeado por agências de fomento ou instituições de ensino e pesquisa, porém, não há impeditivo legal que o próprio autor ou terceiros paguem pelo acesso a números limitados de exemplares dos periódicos.

De modo complementar às taxas supracitadas, destaca-se o modelo de negócio baseado no acesso gratuito aos conteúdos, conhecido como acesso aberto (open access), que tem como características manter a integridade do trabalho e garantir o reconhecimento dos autores da produção (European Science Foundation, 2012). No entanto, Nassi-Caló (2013) destaca que, mesmo que pareça totalmente gratuita, a publicação em acesso aberto requer investimento financeiro, ainda que esse formato seja mais econômico que as revistas que demandam assinaturas ou cobram outras taxas. As revistas com acesso aberto disponibilizam artigos que podem ser lidos gratuitamente por todos, mas os custos devem ser pagos por agências financiadoras e/ou pelos próprios autores. Van Noorden (2013) explica que o fato dos periódicos de acesso aberto ter custos mais baixos e, apesar disso, favorece maior margem de lucro se deve ao modo de publicação totalmente eletrônico (online), sendo desnecessário executar impressões ou configurar paywalls de assinaturas.

Com base no pressuposto teórico, a compreensão do custo real de publicação em revistas científicas situadas no estrato superior do Qualis CAPES possibilitaria escolher o periódico mais apropriado ao campo do conhecimento e as condições financeiras disponíveis. Sendo assim, o objetivo principal do presente estudo é classificar as revistas A1 da área 21 de acordo com as taxas envolvidas no seu processo de publicação.

\section{MATERIAIS E MÉTODOS}

Esta pesquisa, de caráter quantitativo, baseia-se na análise dos periódicos estratificados como A1 e 
selecionados a partir da área de avaliação "Educação Física". Para isso, utilizou-se como material a relação referente ao quadriênio 2013-2016, cedida pelo sistema Qualis CAPES, através da Plataforma Sucupira. Ressalta-se que as demais áreas que compõem a área 21 (Fisioterapia, Fonoaudiologia e Terapia Ocupacional) não apresentaram campo específico para seleção e busca na plataforma.

As consultas aconteceram entre os dias 1 e 12 do mês de Abril de 2019, por meio dos títulos dos periódicos no buscador Google ${ }^{\circledR}$, seguido pelo acesso às páginas webs das próprias revistas ou das editoras. As informações referentes ao custeio incluíram as taxas de submissão, processamento e/ou tramitação, publicação e a cobrança por adicionais. As despesas com o acesso aberto foram atribuídas aos autores, seguindo o modelo de negócio "autor paga" e somadas às demais taxas. Por entender que as assinaturas geralmente são custeadas pelas instituições e/ou agências de fomento e não pelo pesquisador, a sua cobrança foi subtraída da análise. Foram identificados, também, o continente de origem e o fator de impacto dos periódicos, tendo como referência as estatísticas bibliométricas do Journal Citation Reports, edição 2018. Os periódicos foram classificados e ranqueados dos mais baratos para os mais caros. Em caso de igualdade nos valores cobrados, considerou-se o fator de impacto como critério de desempate, seguindo a ordem decrescente para esse índice.

Foram desclassificados os periódicos que não disponibilizaram todas as informações sobre as taxas/ despesas, de modo direto aos autores; ou seja, sem a necessidade de cadastro por login ou via email, e aqueles que não explicitaram ou justificaram os critérios de diferenciação quanto aos valores cobrados.

\section{RESULTADOS}

A listagem fornecida pelo Sistema Qualis apresentou o quantitativo de 239 periódicos. Entretanto, 2 periódicos foram citados em duplicata (Applied Physiology, Nutrition and Metabolism; European Journal of Sport Science) e 1 deles, em triplicata (Plos One). Logo, os títulos repetidos foram extraídos, resultando em 235 revistas. A figura 1 mostra a distribuição geográfica, por continentes, dos periódicos estratificados como A1 para a área 21.

A tabela suplementar 1 apresenta em ordem ascendente quanto ao custo total, a lista classificatória dos periódicos A1 - Área 21, contendo o nome do periódico, ISSN (International Standard Serial Number), fator de impacto, taxas relacionadas à publicação e ao acesso aberto. Os valores cobrados pelos periódicos foram apresentados em todas as moedas disponibilizadas como opção de pagamento. Todavia, para efeito de classificação, consideramos apenas a moeda estrangeira de menor valor após a conversão para real brasileiro, de acordo com a cotação cambial do dia 17 de Abril de 2019. Estabeleceu-se como padrão para comparação dos títulos, o número de 4 páginas por manuscrito, a inserção de apenas uma figura em preto e branco e a não adição de figura colorida ou cor adicional. Nos periódicos Frontiers in Aging Neuroscience; Frontiers in Physiology; Frontiers in Human Neuroscience; Frontiers in Psychology optamos pelos valores referentes aos artigos tipo "A". A modalidade de acesso aberto escolhida foi a gold open. De acordo com os critérios de exclusão preestabelecidos, 13 títulos foram desclassificados.

\section{DISCUSSÃO}

O presente estudo teve como objetivo principal classificar os periódicos $A 1$ da área 21, de acordo com as taxas envolvidas no processo de publicação, seguindo o modelo "autor paga". No ranking apresentado na tabela 1 (suplementar), apenas 8 títulos apresentaram gratuidade para a submissão e publicação pelos autores. Evidenciado pela análise percentual, apenas $3,6 \%$ do total de 222 títulos classificáveis são veiculados no estrato A1 de maneira gratuita. Nassi-Caló (2013) discute sobre o número reduzido de periódicos com custo gratuito de publicação, os quais são geralmente geridos por editoras comerciais e/ou associações e sociedades científicas, ao invés de empresas autônomas, cujas principais formas de arrecadação de receita são as assinaturas por programas governamentais, publicidades, consórcios e outras separatas lucrativas.

Dentre as revistas gratuitas, a New England Journal of Medicine (online), que realiza publicações na área médica desde 1812, obteve a primeira colocação, por apresentar o maior fator de impacto para o estrato A1 na área 21 (79.258). Tecnicamente, quanto maior for o fator de impacto, melhor será sua classificação, de acordo com os recursos métricos de avaliação da produção científica. Segundo Ruiz et al. (2009) o fator de impacto pode incidir sobre a alocação dos recursos fornecidos por agências fomentadoras, além de avaliar a produtividade do autor e atrair novos pesquisadores e fundos de financiamento. Meis et al. (2003) ressaltam que a possibilidade de financiamento de pesquisa cria um ambiente competitivo entre os pesquisadores brasileiros na luta por recursos. No entanto, avaliar a produção científica exclusivamente a partir dessa ferramenta demanda cautela diante da existência de estratégias editoriais de manipulação (Ruiz et al., 2009) como, por exemplo, o aceite de artigos de revisão em detrimento aos artigos originais; o elevado número de autocitações; o oferecimento de suporte estatístico e 


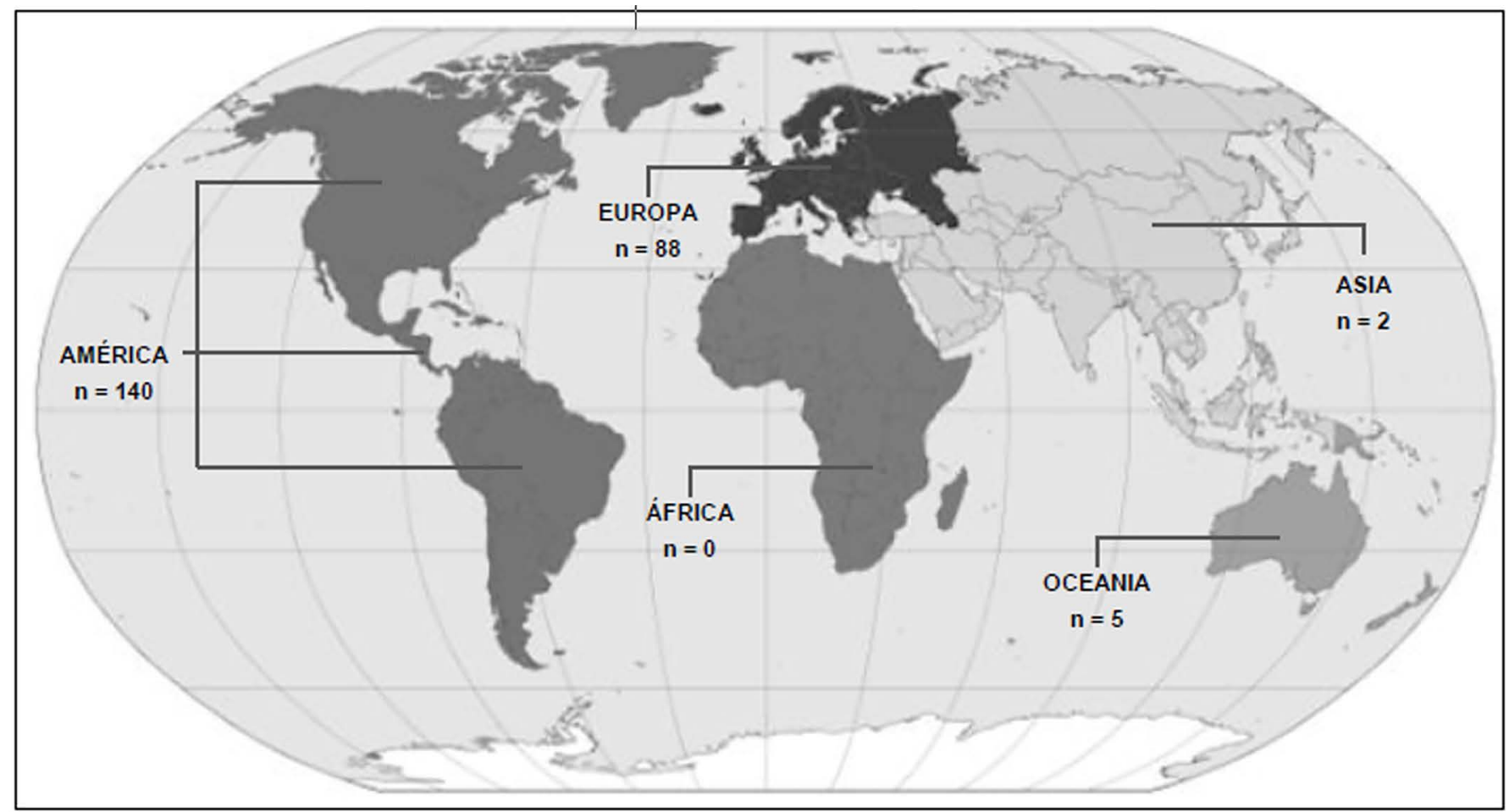

Figura 1. Distribuição geográfica dos periódicos A1 - Área 21.

outras facilidades e a adição de referências a artigos submetidos para apreciação.

Ainda sobre as revistas gratuitas, a 6a colocada, Ear and Hearing (print) e a $7 \underline{a}$ colocada, Journal of Athletic Training, somente obtiveram tal classificação por considerarmos o número limite de 4 páginas por manuscrito e a não inserção de figuras coloridas no corpo do mesmo, respectivamente. Em contrapartida, a Applied Psycholinguistics (print), última colocada dentre as selecionáveis para classificação (222a posição), apresentou um custo total de $\mathrm{R} \$ 61.080,00$ por manuscrito. Por ora, esses valores extrapolam a média calculada para a publicação de um único manuscrito para esse estrato e também a faixa de financiamento do Conselho Nacional de Desenvolvimento Científico e Tecnológico (CNPq) para jovens pesquisadores. Para Van Noorden (2013) e Nassi-Caló (2013), as revistas mais caras deveriam ter como justificativa o fato de serem mais seletivas para o aceite de trabalhos. Obviamente, se o modo de publicação em acesso aberto fosse, de fato, totalmente gratuito o panorama seria diferente. Nesse cenário hipotético, teríamos um número maior de periódicos isentos de cobranças e um custo médio por manuscrito para publicação relativamente mais baixo.

A cobrança para a publicação de artigos científicos tem chamado a atenção de um grupo de pesquisadores brasileiros da Universidade Federal do Rio Grande do Sul sobre a existência de revistas "predatórias" (Marques, 2018). Na prática, essas revistas publicam artigos sem que haja critérios técnico-avaliativos confiáveis, desde que os autores paguem por isso. De acordo com os pesquisadores, esses títulos geralmente não possuem fator de impacto, mas, em alguns casos, podem figurar na listagem fornecida pelo sistema Qualis. Logo, eventualmente, a publicação nessas revistas representaria um desperdício de recursos por parte das agências fomentadoras de pesquisa como a CAPES e o CNPq, prejudicando, assim, diversos programas de pós-graduação brasileiros. Contudo, a checagem de tal conduta não foi objeto do presente estudo, mas caberia maior discussão no meio acadêmico.

Outro resultado relevante diz respeito à distribuição geográfica dos periódicos em nível continental. A figura 1 mostra que $97,02 \%$ dos títulos estão concentrados na América (59,57\%) e Europa (37,45\%). O restante, em menor parcela, está distribuído entre a Oceania $(2,13 \%)$ e a Ásia $(0,85 \%)$. Nenhum periódico desse estrato é oriundo do continente africano. Essa distribuição geográfica reflete o incentivo financeiro proveniente de empresas gestoras e financiamentos para o campo científico e tecnológico dos continentes e países de maior verificação. Meis et al. (2003) mencionam as dificuldades enfrentadas por pesquisadores, tendo em vista a demanda de custeio de suas publicações em periódicos melhor qualificados. Essa questão polariza países/continentes que retém o poder científico e os que se tornam marginalizados e menos aceitos em âmbito mundial. Ainda, reconhecidamente, América e Europa possuem a supremacia na área biomédica e 
biotecnológica mundial (European Science Foundation, 2012), o que impacta diretamente na análise realizada sobre os periódicos classificados como A1 para a área 21 , no presente estudo.

Do total observado na América, apenas 2 revistas são brasileiras: Diabetology \& Metabolic Syndrome (ISSN: 1758-5996) e Jornal de Pediatria - versões online (ISSN: 1678-4782) e impressa (ISSN: 00217557), oque pode caracterizar, portanto, um indicador de pouco incentivo à divulgação científica no país. Uma possível explicação para essa discrepância numérica para os periódicos internacionais parece estar relacionada às dificuldades enfrentadas pelos periódicos nacionais, como, por exemplo, a ausência de padrão editorial e o baixo número de assinaturas e de leitores interessados (Job, 2017). Sacardo (2007) reconhece que, nos moldes atuais, a internacionalização do conhecimento, através da publicação em periódicos internacionais, é necessária para a obtenção de melhor classificação dos programas de pós-graduação. Nesse sentido, alguns grupos de pesquisa consideram que as publicações em língua inglesa são mais relevantes para a comunidade acadêmica e científica mundial, demonstrando que os países desenvolvidos devem obter como prioridade o atendimento de seus interesses (Marchlewski et al., 2011). Dos periódicos nacionais supracitados, somente a versão online do Jornal de Pediatria aceita a submissão em língua portuguesa. De fato, a internacionalização do conhecimento acadêmico desconsidera o público leitor a quem se destina a produção, as possíveis regionalizações de questões no âmbito nacional e, ainda, amplia assimetrias de áreas como as publicações inseridas no campo educacional ou do esporte, também presentes e analisadas pela área 21 da CAPES. Essas questões merecem melhor reflexão para o aceite de novos índices de classificação para a área, os quais considerem critérios qualitativos, além dos quantitativos já assumidos (Zingano, 2017).

Yamamoto et al. (2002) apontam que a ausência de $70 \%$ dos periódicos latino-americanos em indexadores internacionais relevantes caracteriza uma baixa expressão dos países latinos em publicação. Parcialmente, esse dado pode ser justificado pela disseminação do modo de publicação em acesso aberto. Nacionalmente, nos últimos anos, tal política de acesso aberto aos periódicos, através das bibliotecas eletrônicas, tem sido ampliada e subsidiada pelos governos federal (Portal de Periódicos CAPES) e estadual (Scientific Electronic Library Online - SciELO) (Príncipe e Barradas, 2013; Nassi-Caló, 2013).
Como limitação, destaca-se a sazonalidade do sistema Qualis Periódicos, que permite que um título estratificado como A1 na tiragem 2013-2016 possa receber conceito diferente na próxima avaliação. Além disso, os valores cobrados e disponibilizados pelas revistas podem sofrer reajustes a qualquer momento, assim como as moedas estrangeiras sofrem com a volatilidade oscilatória do câmbio. Por fim, o artigo propõe uma estratégia de classificação das revistas e não critérios para nivelamento da pós-graduação. No entanto, os dados observados permitem diferentes reflexões sobre o sistema de produtividade acadêmico científico, principalmente com viés político-econômico.

\section{CONCLUSÃO}

Conclui-se que poucas revistas científicas $\mathrm{A} 1 \mathrm{da}$ área 21 são totalmente gratuitas para publicação, seguindo o modelo "autor paga". Tendo em vista o cenário de recursos limitados, isso impactaria diretamente a produtividade científica nacional, principalmente para cientistas em início de carreira e áreas consideradas "secundárias", cujos financiamentos são baixos e dificilmente cobrem os custos das pesquisas e publicações. Embora a classificação dos periódicos esteja baseada no quadriênio 2013-2016, nosso estudo auxiliará, de modo atemporal, na escolha da melhor revista sob a perspectiva financeira, além de configurarse como material crítico ao sistema de produtividade científica. Sugerem-se novos estudos sobre o tema, ampliando as análises e discussões sobre as formas de classificação, estratificação e divisão por cursos.

\section{AGRADECIMENTOS}

Os autores agradecem ao Conselho Nacional de Desenvolvimento Científico e Tecnológico (CNPq), a Pró-Reitoria de Pesquisa e Pós-Graduação (PROPPG/ UEMG) e a Fundação de Amparo a Pesquisa de Minas Gerais (FAPEMIG) pelo apoio financeiro concedido através do edital BIP/2017 (no 00262-17).

\section{APOIO FINANCEIRO}

Conselho Nacional de Desenvolvimento Científico e Tecnológico (CNPq) e a Fundação de Amparo a Pesquisa de Minas Gerais (FAPEMIG) pelo apoio financeiro concedido através do edital BIP/2017 (processo $\mathrm{n}$ 000262-17).

\section{REFERÊNCIAS}

Bicas, HEA, Chamon W. Sobre o preço e valor das publicações científicas: reclamação ou indignação? Arq Bras Oftalmol., 75(3), p. 157 - 158, 2012.

European Science Foundation. Open Access in Biomedical Research. Science Police Briefing. September, 2012. 
Fundação Capes. Documento de Área 2013. Ministério da Educação. Disponível em:http://www.capes.gov.br/avaliacao/instrumentosde-apoio/documentos-de-area\#footer. Acesso em: 09 Jun 2018.

Job I. Avaliação de periódicos nacionais na área de Educação Física [periódico na internet]. [acessado 2017 Jun 15]; [cerca de 13p.] Disponível em: http://www.lume.ufrgs.br/bitstream/ handle/10183/10691/000598933.pdf? sequence=1

Marchlewski C, Silva PM, Soriano JB. A influência do sistema de avaliação Qualis na produção de conhecimento científico: algumas reflexões sobre a Educação Física. Motriz, v.17, n.1, p. 104 - 116, 2011.

Marques F. A escalada da discórdia. Novos critérios do sistema QUALIS, da Capes, recebem críticas da comunidade científica. Pesquisa FAPESP, Junho, v.160, p. 32 - 34, 2009.

Marques F. A sombra das revistas predatórias no Brasil. Pesquisa FAPESP, Agosto, v. 270, p. 8 - 10, 2018.

Meis L, Carmo MS, Meis C. Impact factors: just part of a research treadmill. Nature, v.424, n.14, August, p. 723, 2003.

Nassi-Caló L. Quanto custa publicar em acesso aberto? [online]. SciELO em Perspectiva, 2013 [viewed 27June2017]. Available from: http://blog.scielo.org/blog/2013/09/18/ quanto-custa-publicar-em-acesso-aberto/
Príncipe E, Barradas MM. Modelos de negócios de revistas científicas brasileiras: Author Pay. Encontro Nacional de Editores Científicos, v.14, 2013.

Ruiz MA, Greco OT, Braile DM. Fator de impacto: importância e influência no meio editorial, acadêmico e científico. Rev Bras Cir Cardiovasc 2009 v.24, n.3, p. 273-278, 2009.

Sacardo MS. Reflexões acerca da pós-graduação brasileira: o impacto dessa política na área da Educação Física. Rev. Bras. Cienc. Esporte, v.29, n.1, set., p. 75 - 88, 2007.

Van Noorden R. Open access: the true cost of science publishing. Nature, v.495, n.7442, March, p. 426-429, 2013.

Yamamoto OH, Menandro PRM, Koller SH, Lobianco AC, Hutz CS, Bueno JLO, Guedes MC. Avaliação de periódicos científicos brasileiros da área da psicologia. Ciência da informação. Brasília. v.31, n.2 (maio/agosto), p. 163 - 177, 2002.

Zingano M. Sobre o Qualis Periódicos 2015 - Filosofia e o risco de Sepukku. Revista Adusp. São Paulo. n.60, Maio, p. 118 123, 2017.

Open Access - broad readership, high impact. Springer, September, 2012. 


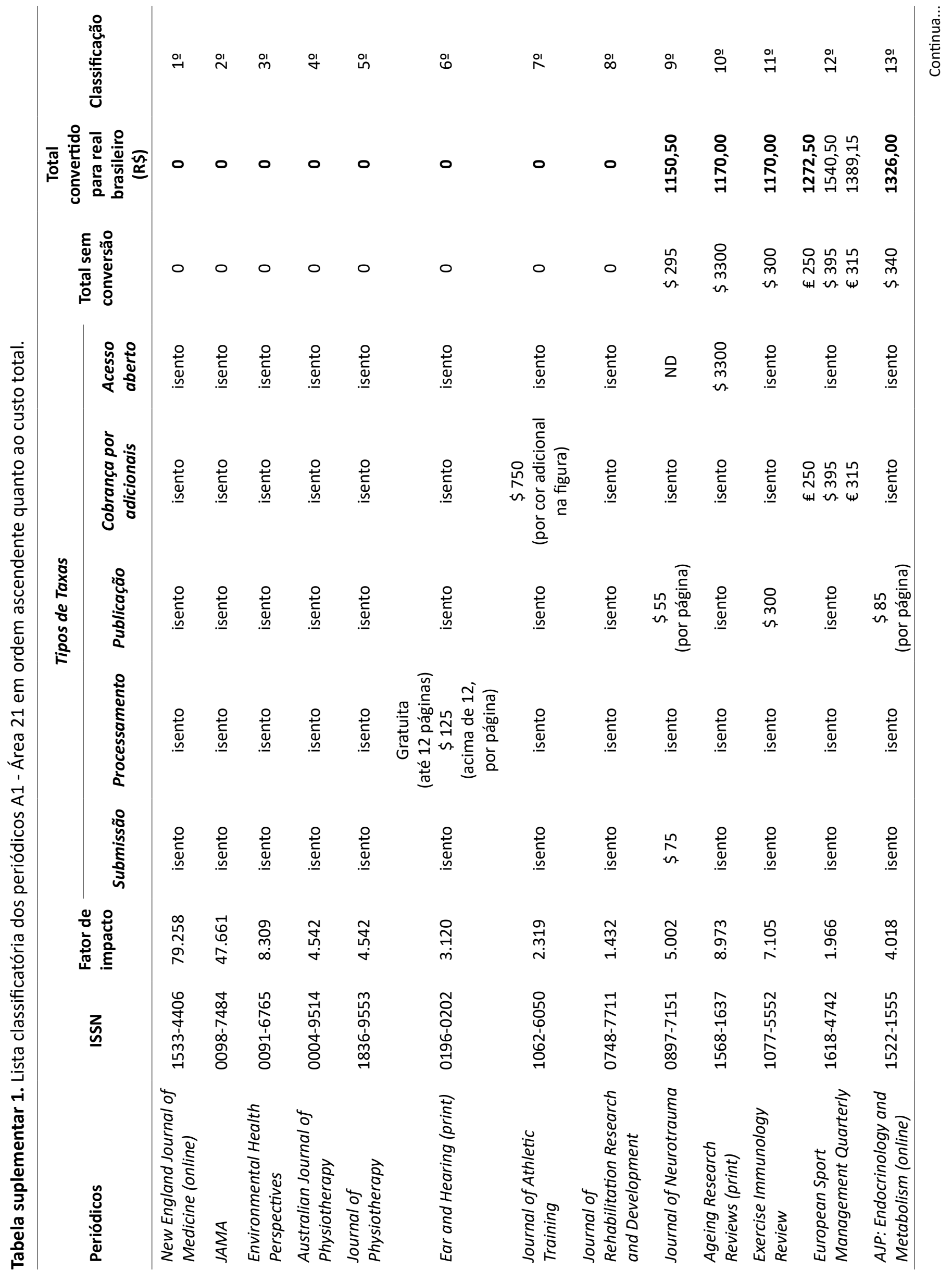




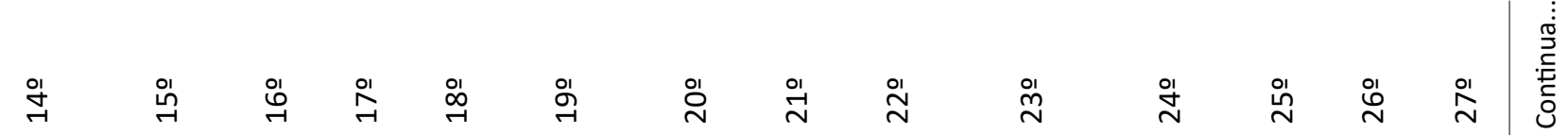

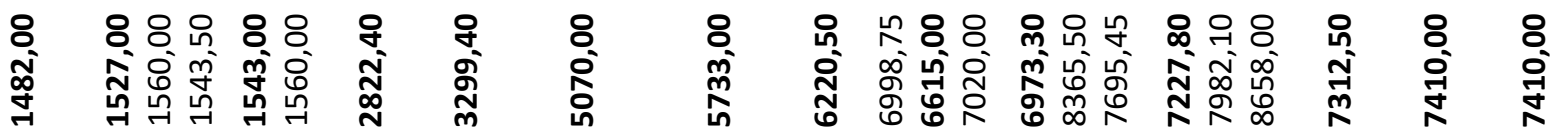

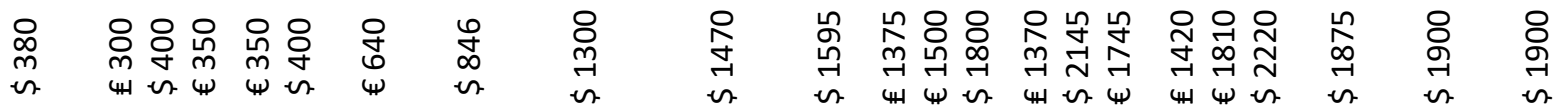

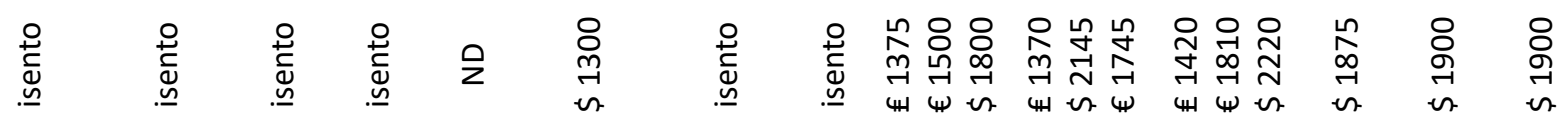

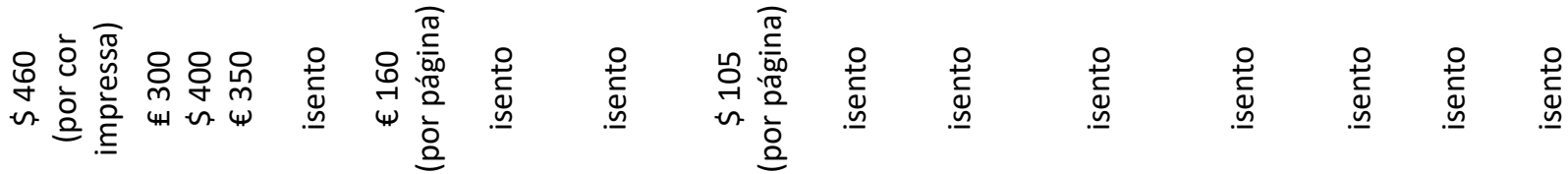

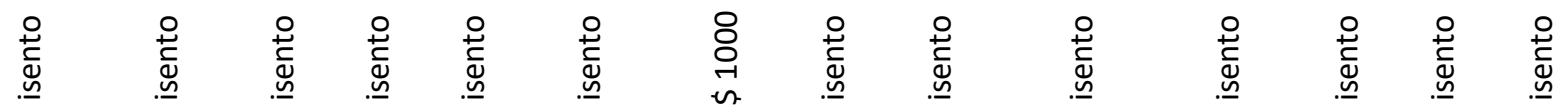

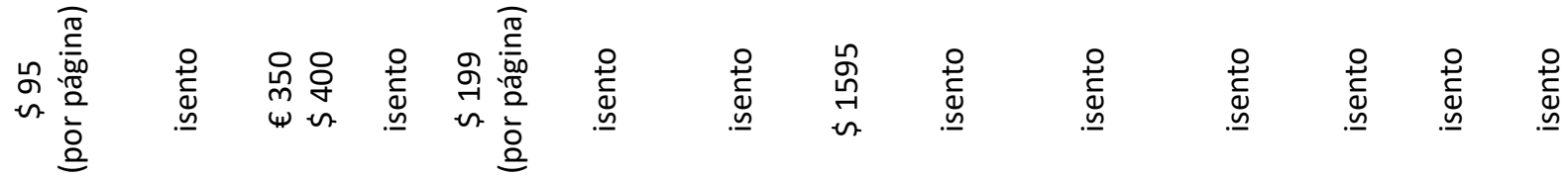

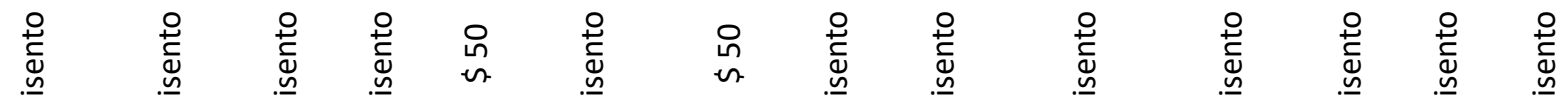

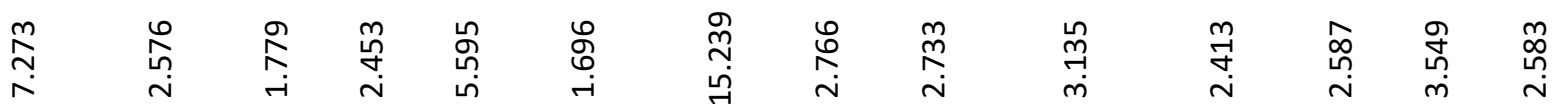

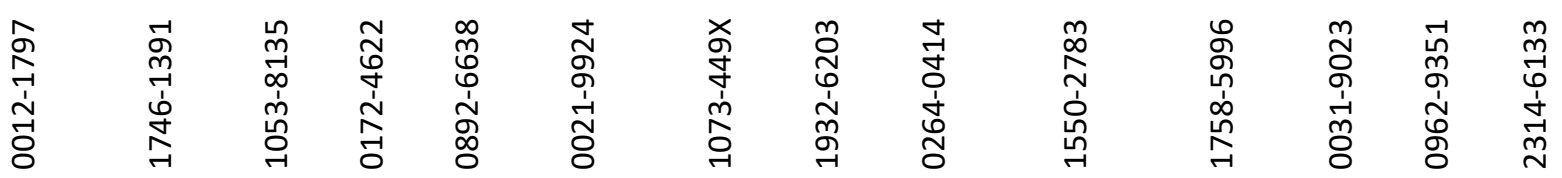

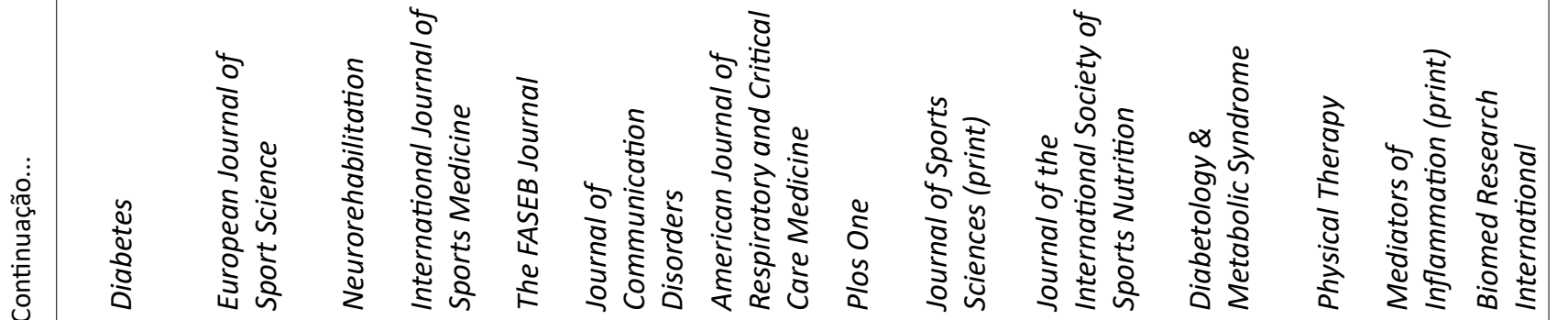




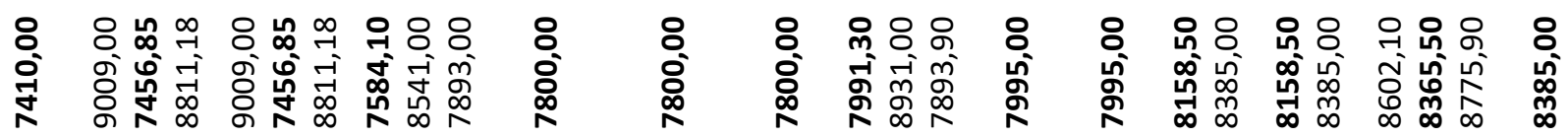

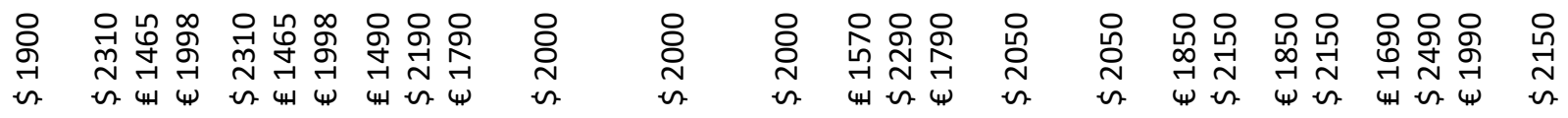

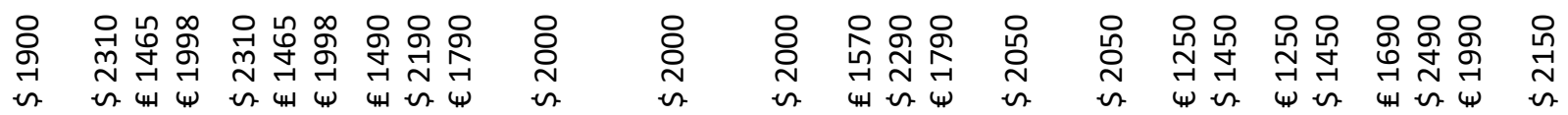

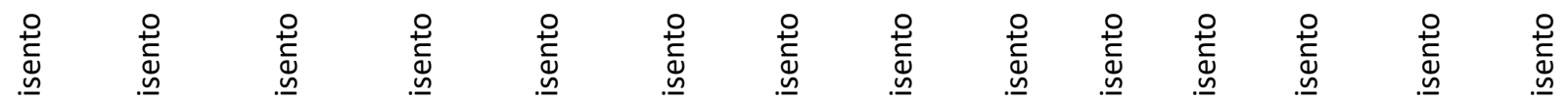

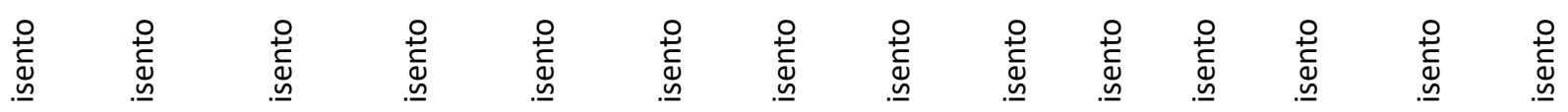

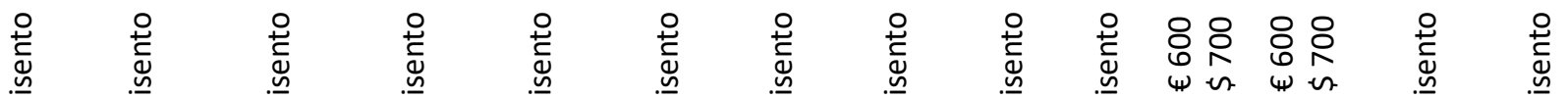

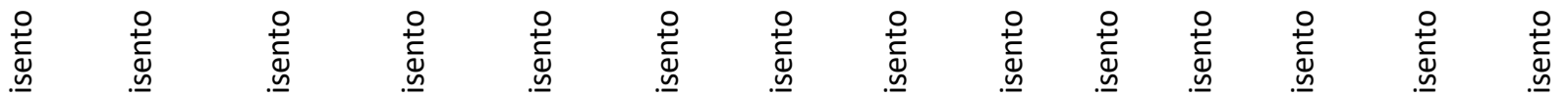

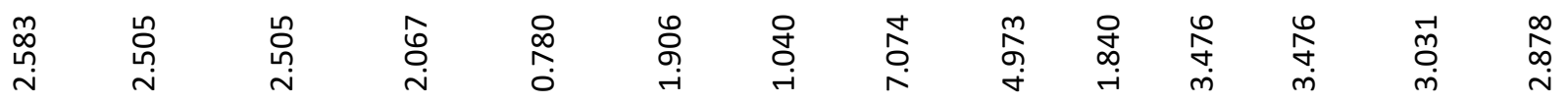

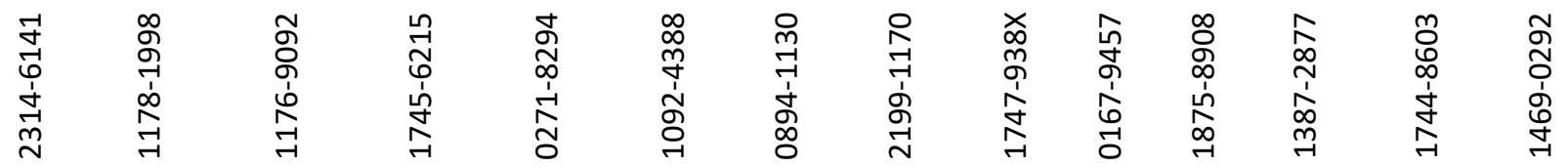

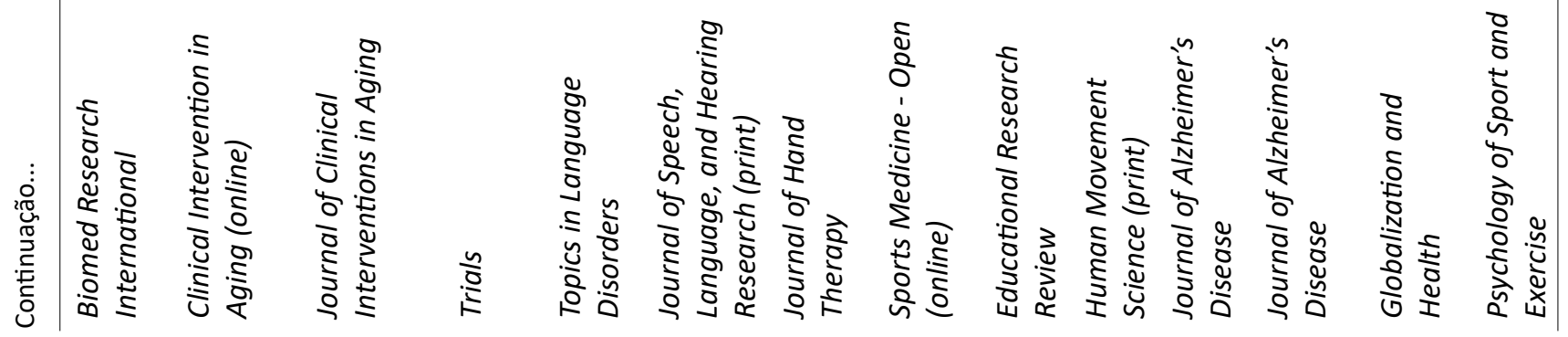




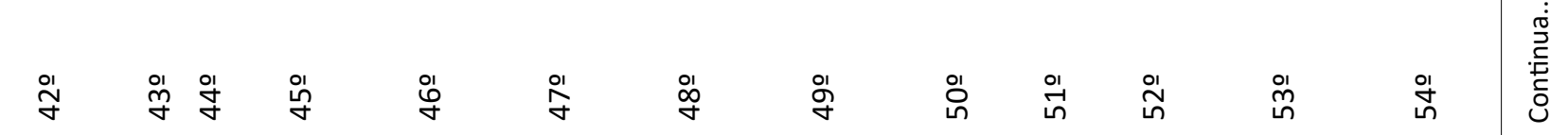

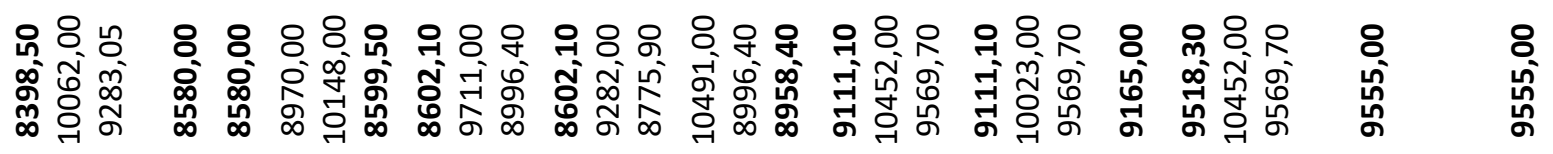

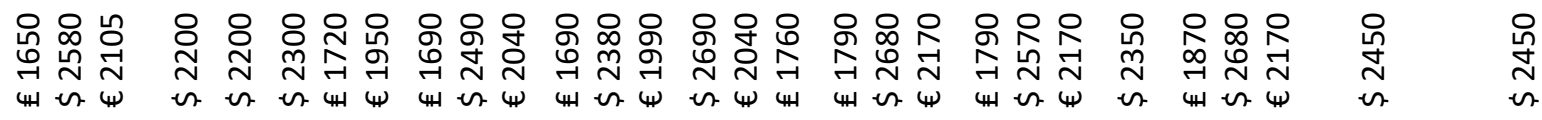

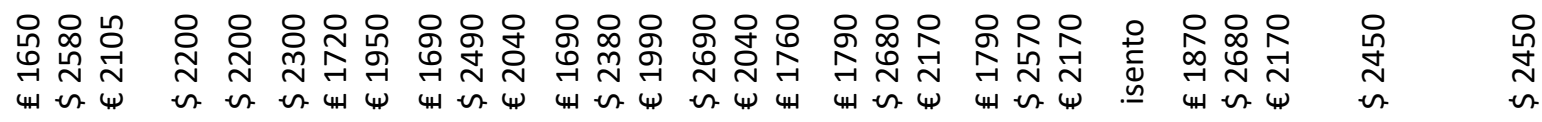

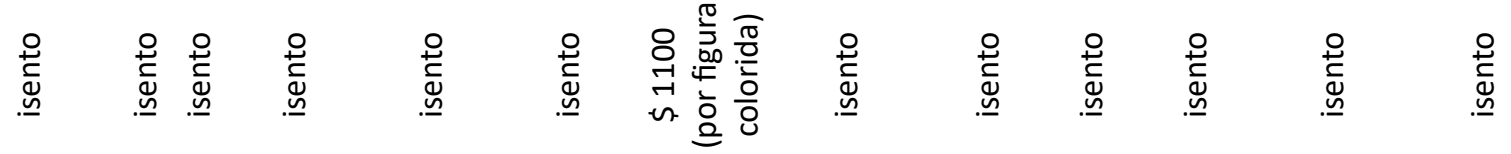

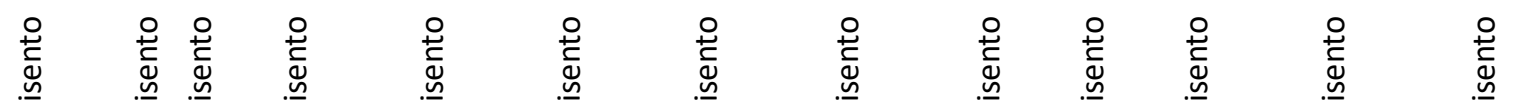

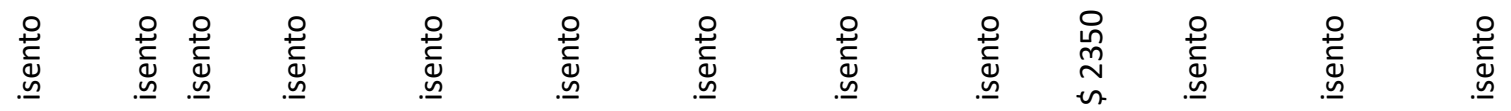

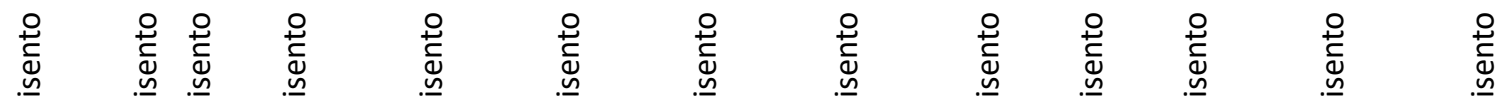

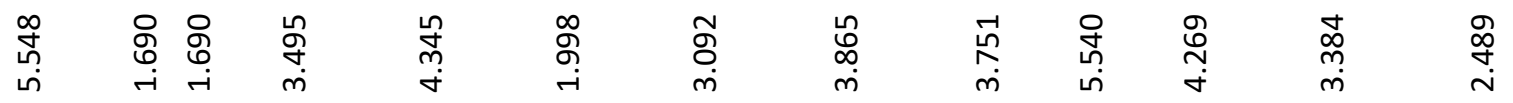

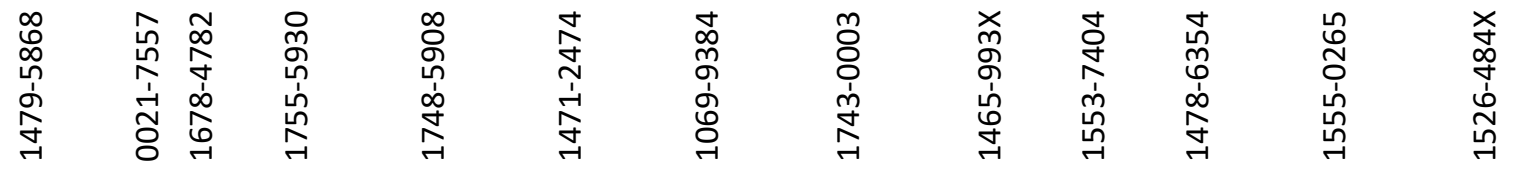

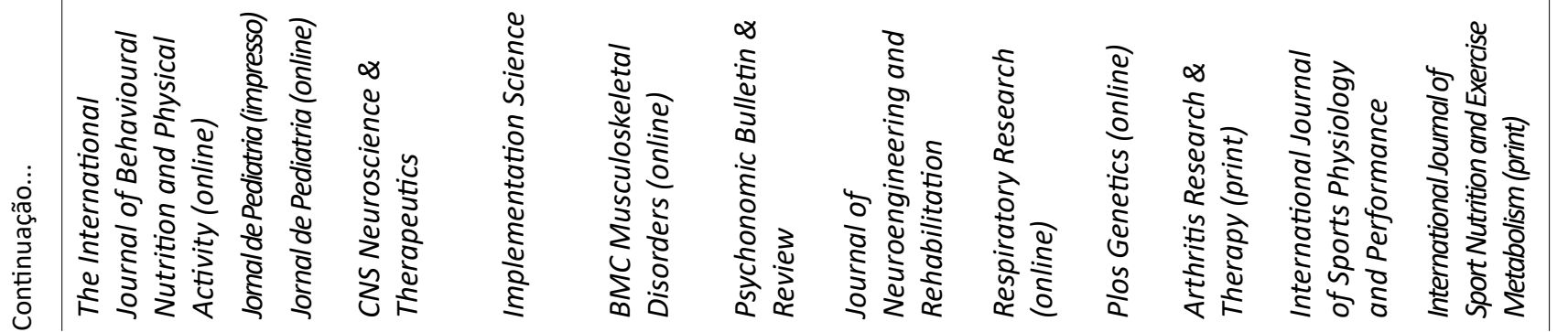




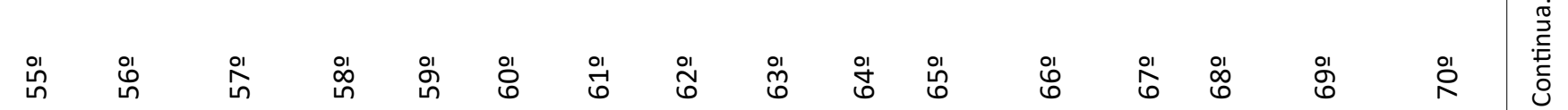

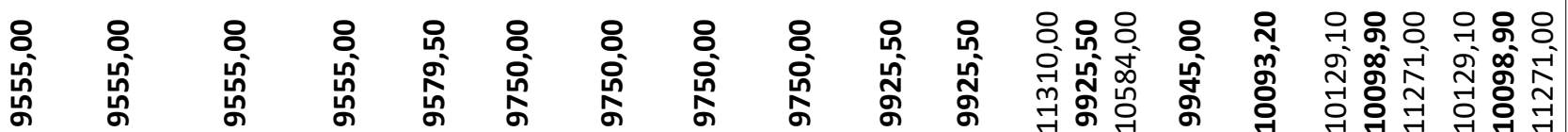

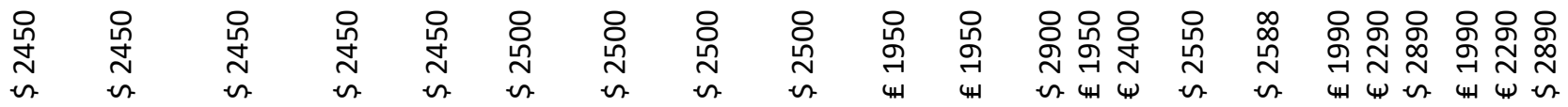

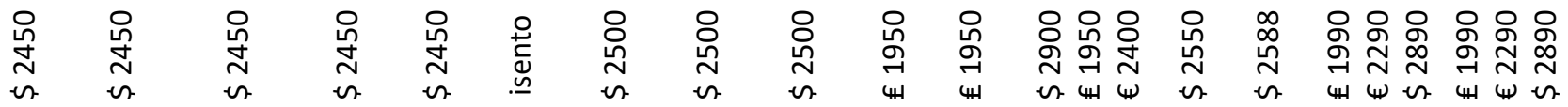

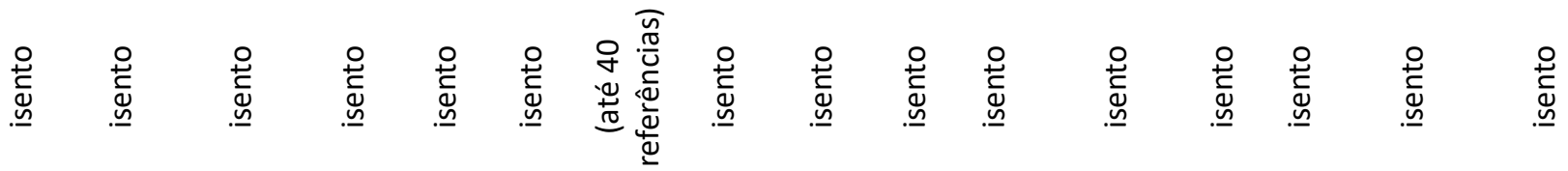

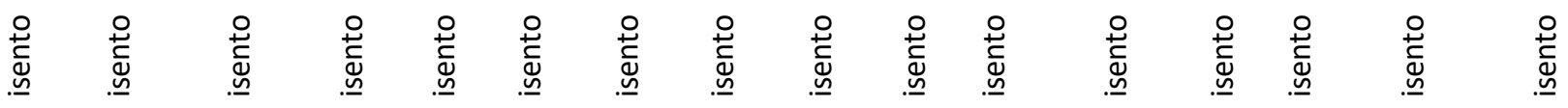

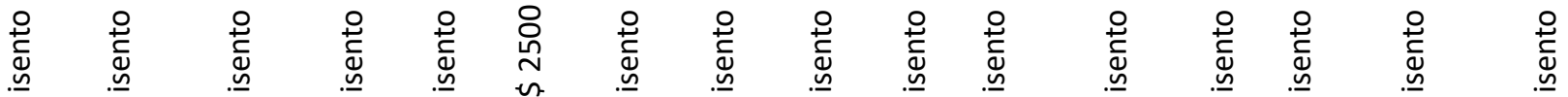

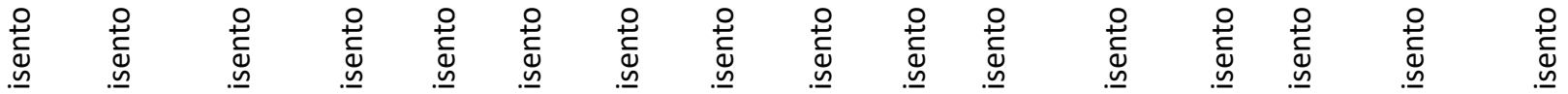

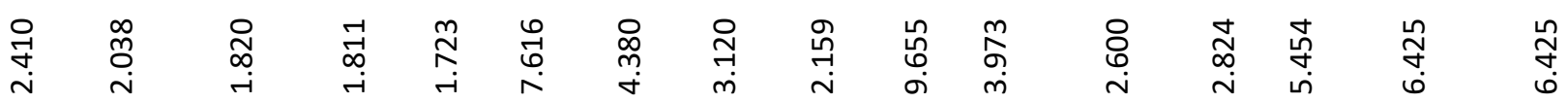

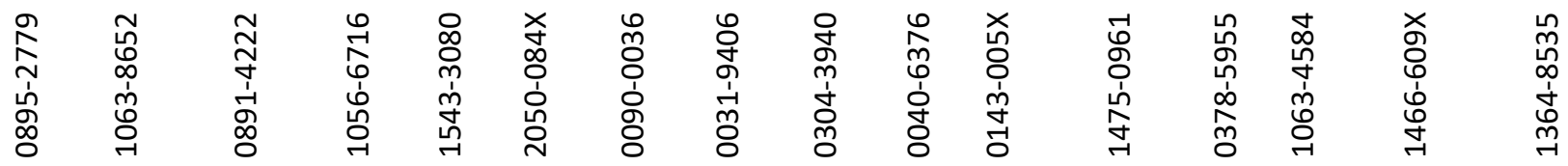

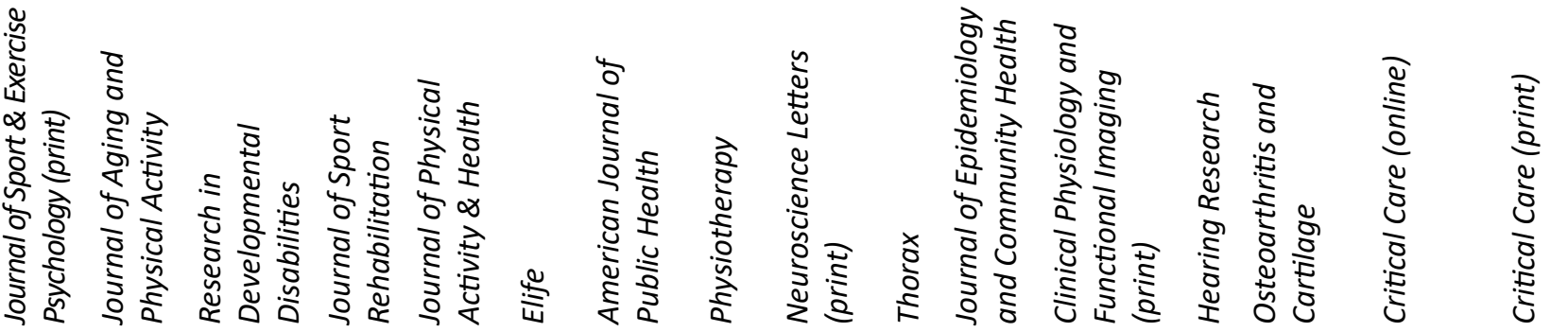




\begin{tabular}{|c|c|c|c|c|c|c|c|c|c|c|}
\hline$\stackrel{\circ}{i}$ & $\stackrel{\stackrel{2}{N}}{ }$ & $\stackrel{\grave{m}}{N}$ & $\stackrel{\text { 암 }}{\circ}$ & 㖞 & $\stackrel{0}{\circ}$ & 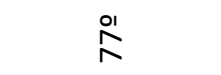 & $\stackrel{\circ}{\stackrel{1}{\wedge}}$ & 임 & 잉 & $\stackrel{\text { II }}{\infty}$ \\
\hline $\begin{array}{l}8 \\
0 \\
0 \\
\text { वें } \\
\text { ô }\end{array}$ & $\begin{array}{l}8 \\
0 \\
0 \\
0 \\
0 \\
0\end{array}$ & 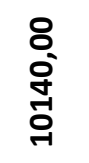 & 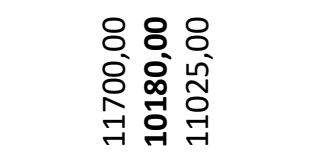 & 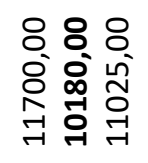 & 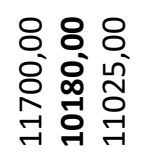 & 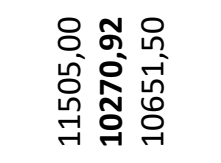 & 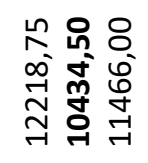 & 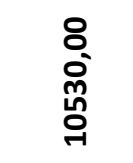 & 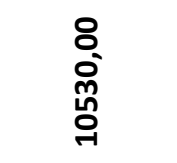 & 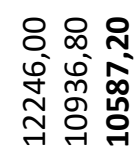 \\
\hline $\begin{array}{l}8 \\
\stackrel{0}{N} \\
n\end{array}$ & $\begin{array}{l}\stackrel{8}{0} \\
\stackrel{0}{N} \\
n\end{array}$ & $\begin{array}{l}8 \\
\stackrel{0}{N} \\
n\end{array}$ & 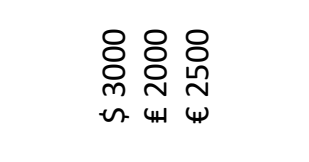 & 焦 & 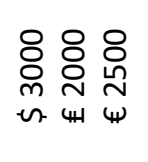 & 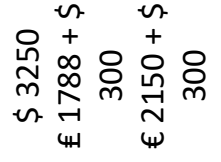 & 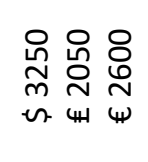 & $\begin{array}{l}\stackrel{8}{2} \\
\stackrel{n}{n}\end{array}$ & 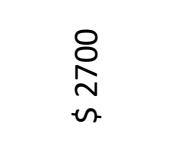 & 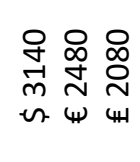 \\
\hline $\begin{array}{l}8 \\
\stackrel{8}{N} \\
n\end{array}$ & $\begin{array}{l}8 \\
\text { d } \\
\text { n. }\end{array}$ & 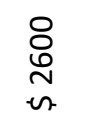 & ০ & 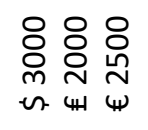 & 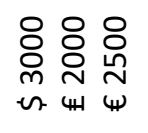 & 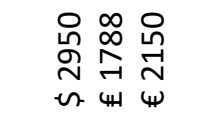 & 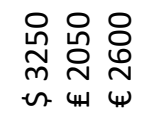 & 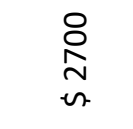 & \begin{tabular}{l}
8 \\
\multirow{2}{*}{} \\
$n$
\end{tabular} & 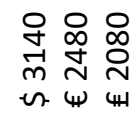 \\
\hline 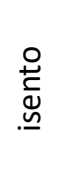 & 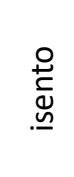 & 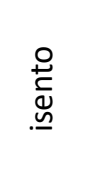 & 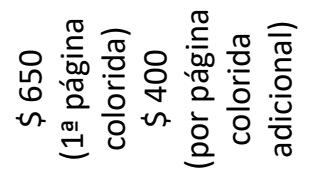 & 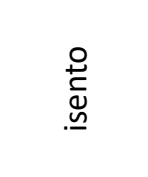 & 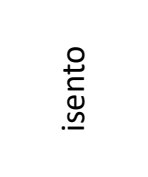 & 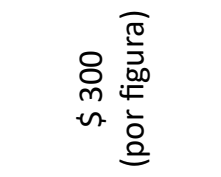 & $\begin{array}{l}\stackrel{0}{*} \\
\stackrel{d}{d} \\
. \underline{M}\end{array}$ & 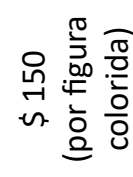 & $\begin{array}{l}\stackrel{0}{ \pm} \\
\stackrel{0}{v} \\
. \underline{M}\end{array}$ & $\begin{array}{l}\stackrel{0}{1} \\
\stackrel{D}{D} \\
. \underline{M}\end{array}$ \\
\hline $\begin{array}{l}\stackrel{0}{\stackrel{2}{c}} \\
\stackrel{\underline{D}}{\underline{n}}\end{array}$ & 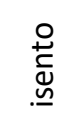 & 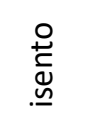 & $\begin{array}{l}\stackrel{0}{*} \\
\stackrel{0}{\Phi} \\
. \underline{M}\end{array}$ & $\begin{array}{l}\stackrel{0}{*} \\
\stackrel{ \pm}{ \pm} \\
. \underline{\underline{y}}\end{array}$ & $\begin{array}{l}\stackrel{0}{*} \\
\stackrel{0}{0} \\
. \underline{\underline{M}}\end{array}$ & $\begin{array}{l}\stackrel{0}{*} \\
\stackrel{0}{0} \\
. \underline{\underline{n}}\end{array}$ & $\begin{array}{l}\stackrel{0}{*} \\
\stackrel{ \pm}{ \pm} \\
. \underline{\underline{N}}\end{array}$ & 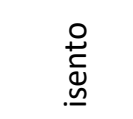 & 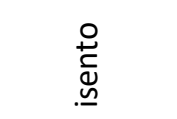 & 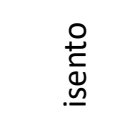 \\
\hline $\begin{array}{l}\stackrel{0}{0} \\
\stackrel{0}{0} \\
. \underline{M}\end{array}$ & $\begin{array}{l}\stackrel{0}{ \pm} \\
\stackrel{\mathbb{d}}{\underline{M}}\end{array}$ & $\begin{array}{l}\stackrel{0}{ \pm} \\
\stackrel{\mathbb{U}}{\underline{M}}\end{array}$ & 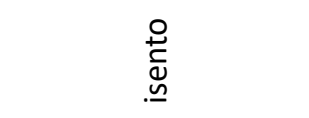 & 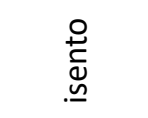 & 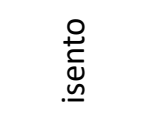 & 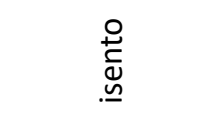 & $\begin{array}{l}\stackrel{0}{*} \\
\stackrel{d}{d} \\
. \underline{M}\end{array}$ & $\begin{array}{l}\stackrel{0}{ \pm} \\
\stackrel{ \pm}{ \pm} \\
. \underline{M}\end{array}$ & $\begin{array}{l}\stackrel{0}{ \pm} \\
\stackrel{\mathbb{U}}{\underline{M}}\end{array}$ & $\begin{array}{l}\stackrel{0}{ \pm} \\
\stackrel{ \pm}{ \pm} \\
. \underline{M}\end{array}$ \\
\hline $\begin{array}{l}\stackrel{0}{0} \\
\stackrel{0}{0} \\
. \underline{M}\end{array}$ & 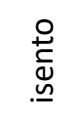 & $\begin{array}{l}\stackrel{0}{ \pm} \\
\stackrel{\mathbb{U}}{\underline{M}}\end{array}$ & 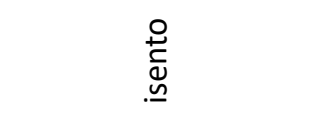 & 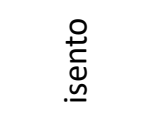 & 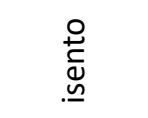 & 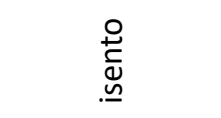 & $\begin{array}{l}\stackrel{0}{*} \\
\stackrel{d}{d} \\
. \underline{M}\end{array}$ & $\begin{array}{l}\stackrel{0}{ \pm} \\
\stackrel{ \pm}{ \pm} \\
. \underline{M}\end{array}$ & 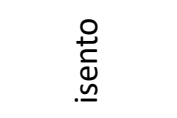 & 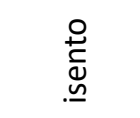 \\
\hline 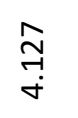 & 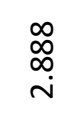 & 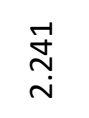 & 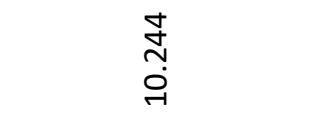 & $\underset{\substack{\sim \\
\infty}}{\stackrel{d}{N}}$ & $\begin{array}{l}\text { ڤ్ } \\
\text { ì }\end{array}$ & $\stackrel{m}{\stackrel{m}{n}}$ & $\begin{array}{l}\text { 곡 } \\
\text { ㄱ. }\end{array}$ & $\begin{array}{l}\text { ஜ̆ } \\
\text { ì }\end{array}$ & $\begin{array}{l}\mathscr{L}_{\infty} \\
\stackrel{-}{-}\end{array}$ & $\underset{\text { I }}{\text { g }}$ \\
\hline 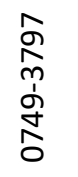 & 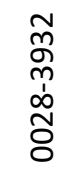 & \begin{tabular}{l}
$m$ \\
\multirow{2}{+}{} \\
\multirow{1}{0}{} \\
6 \\
0 \\
0
\end{tabular} & 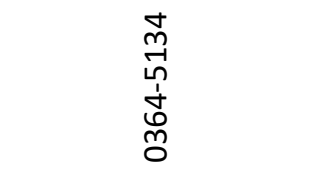 & $\begin{array}{l}\stackrel{\sim}{\infty} \\
\stackrel{1}{1} \\
\stackrel{n}{1} \\
\stackrel{1}{\infty} \\
\infty \\
0\end{array}$ & 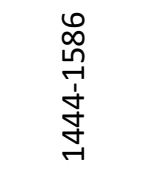 & 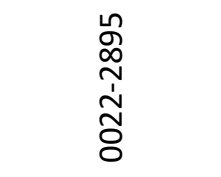 & $\begin{array}{l}\text { ने } \\
\text { مे } \\
\text { ᄋ̆ } \\
\text { ㄱ. }\end{array}$ & 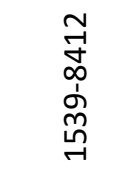 & 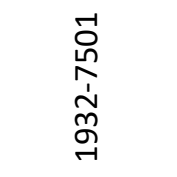 & $\begin{array}{l}\overrightarrow{1} \\
\infty \\
\infty \\
0 \\
0 \\
0\end{array}$ \\
\hline 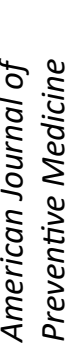 & $\begin{array}{l}\frac{0}{5} \\
\frac{1}{0} \\
\frac{1}{5} \\
\frac{1}{0} \\
0 \\
5 \\
2\end{array}$ & 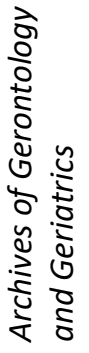 & 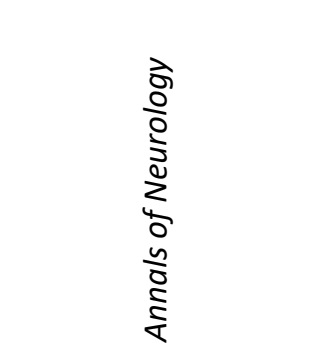 & 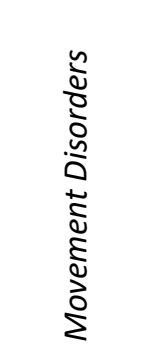 & 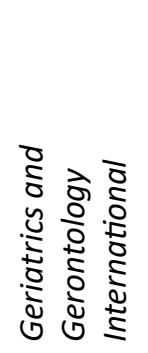 & 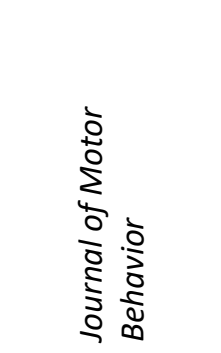 & 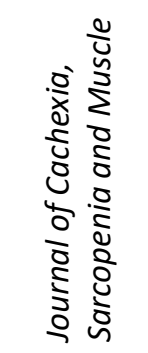 & 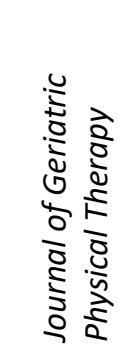 & 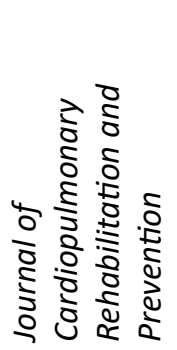 & 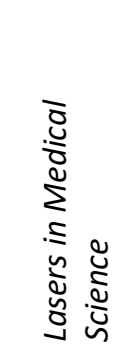 \\
\hline
\end{tabular}




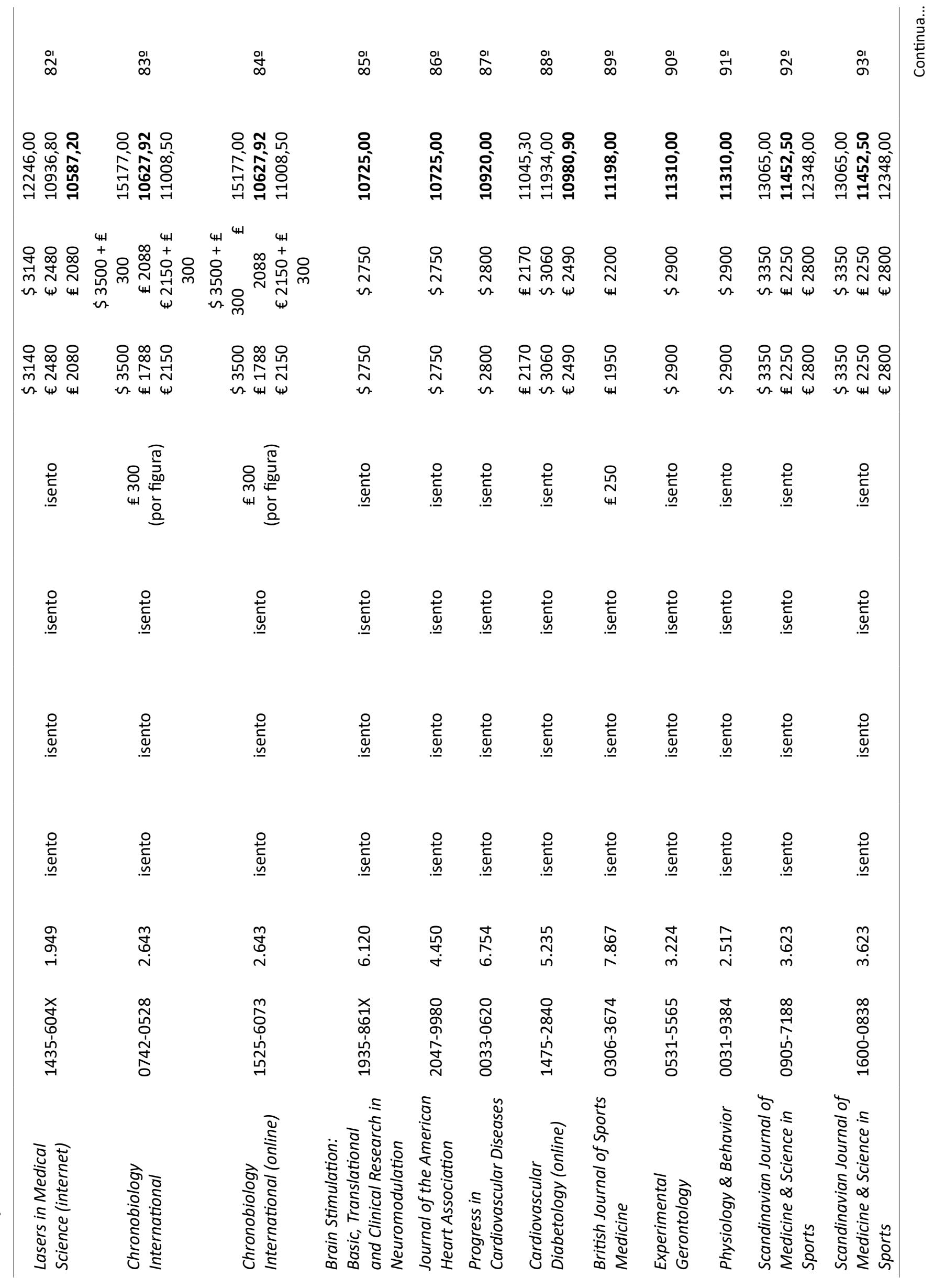




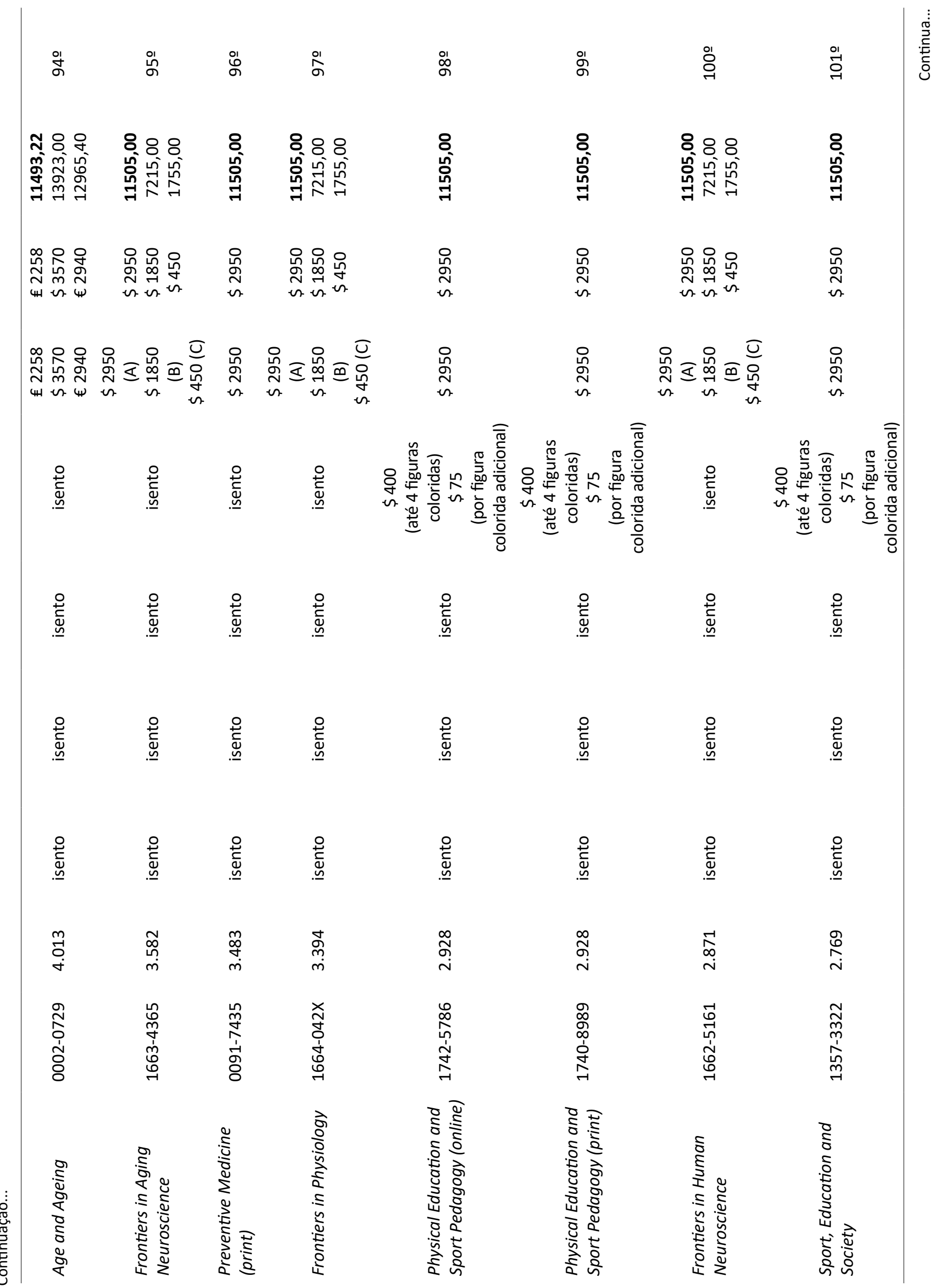




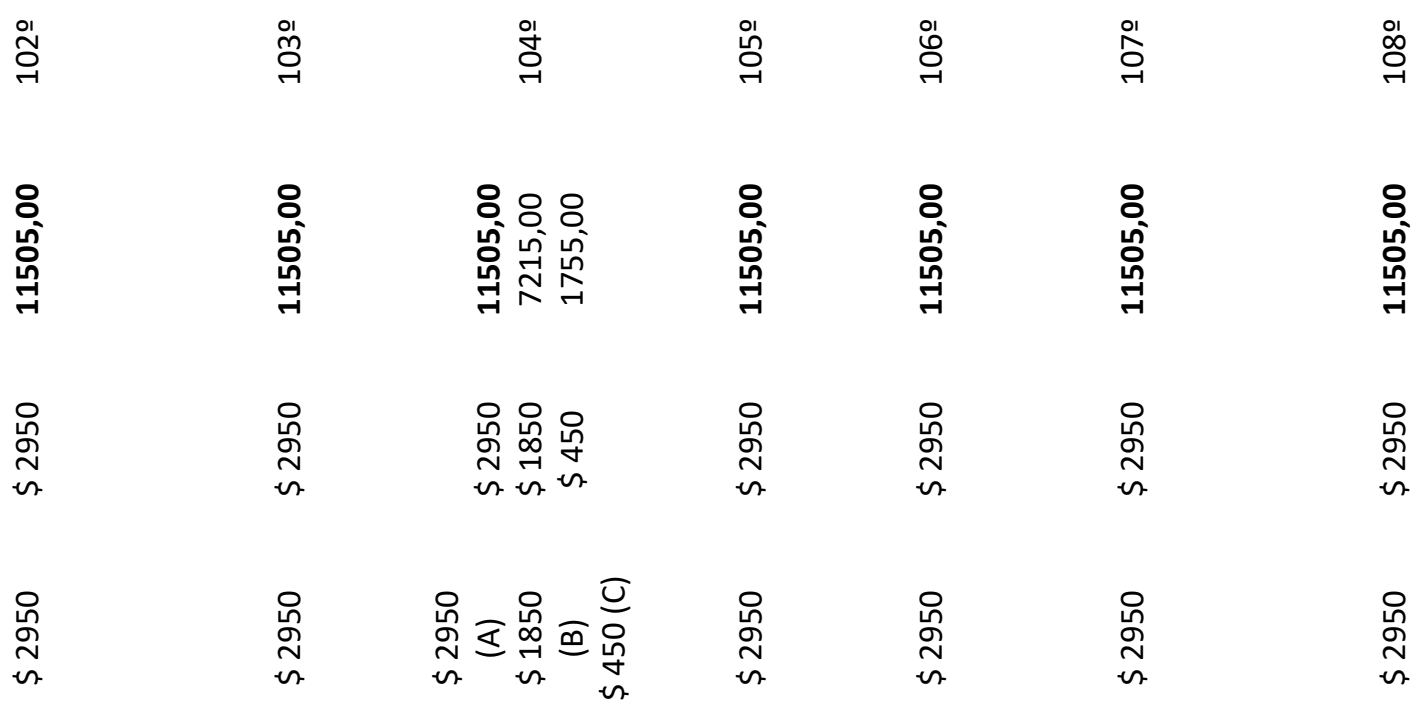

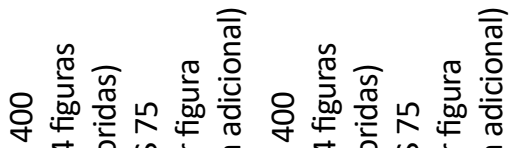

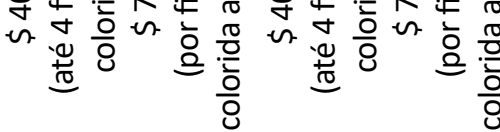

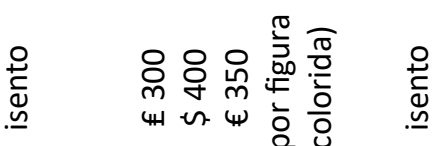

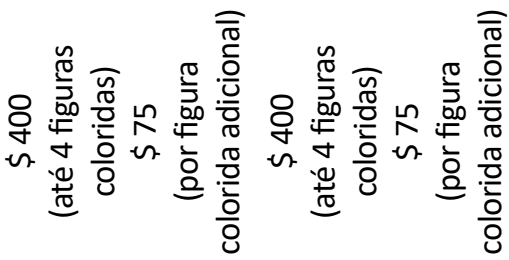

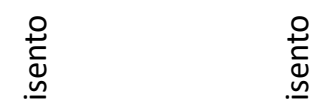

$\stackrel{ }{\stackrel{0}{0}}$

$\begin{array}{ll}\stackrel{0}{+} & \stackrel{0}{*} \\ \stackrel{0}{c} & \underline{0}\end{array}$

$\underset{\substack{0 \\ \stackrel{0}{0}}}{\underline{M}}$

$\stackrel{0}{\stackrel{0}{2}}$

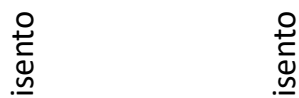

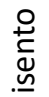

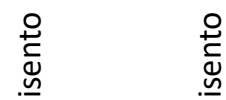

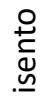

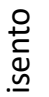

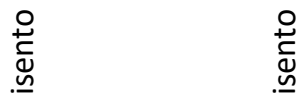

$\stackrel{ }{\stackrel{0}{0}}$

$\begin{array}{ll}\stackrel{0}{+} & \stackrel{0}{ \pm} \\ \stackrel{ \pm}{ \pm} & \underline{.}\end{array}$

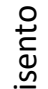

$\stackrel{ }{\stackrel{0}{*}}$

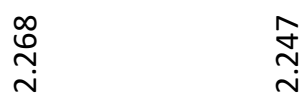

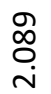

$\stackrel{\overrightarrow{9}}{\stackrel{7}{+}}$

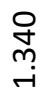

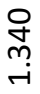

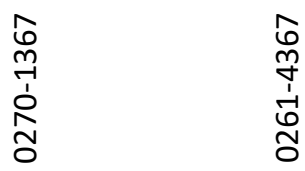

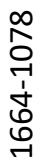

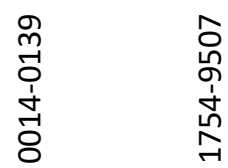

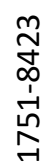

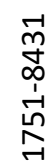

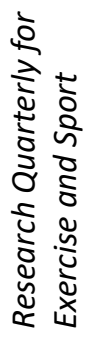

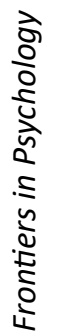

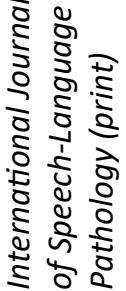

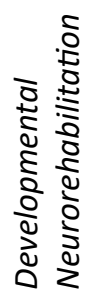

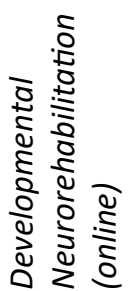




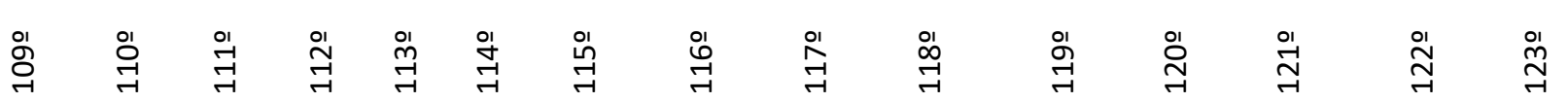

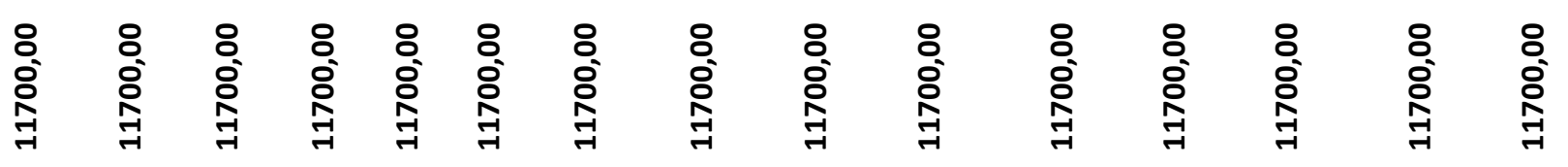

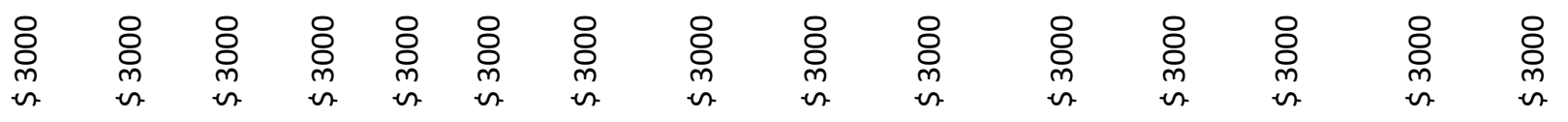

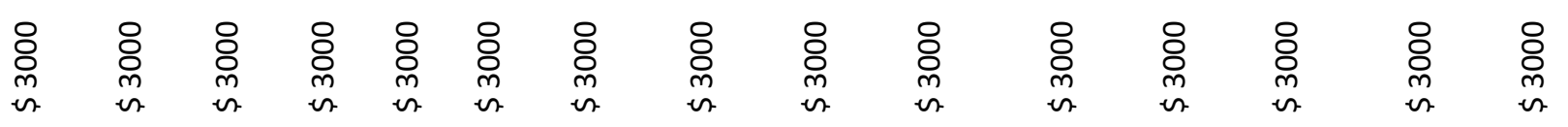

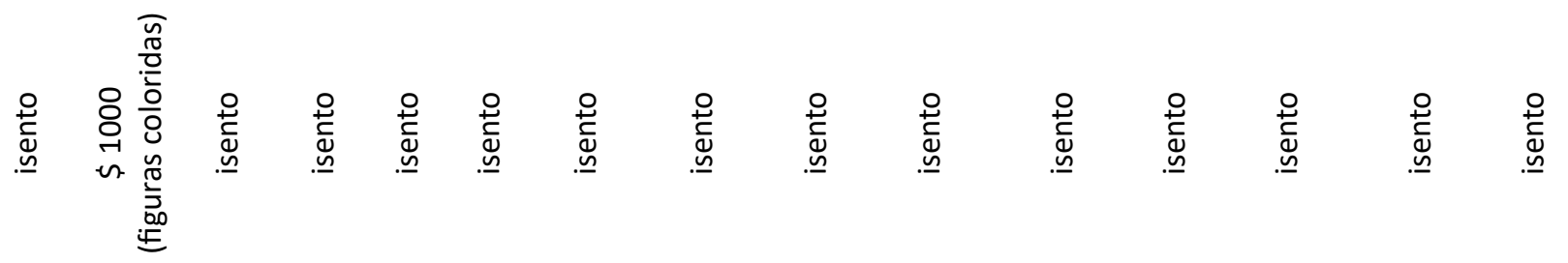

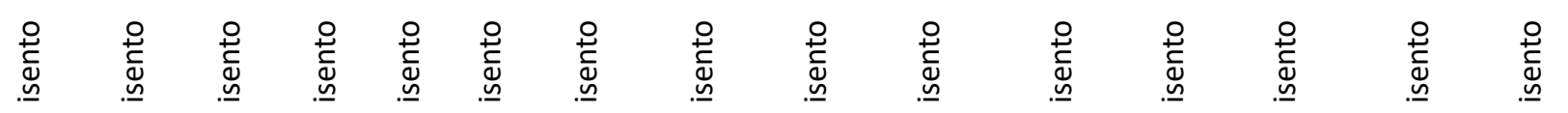

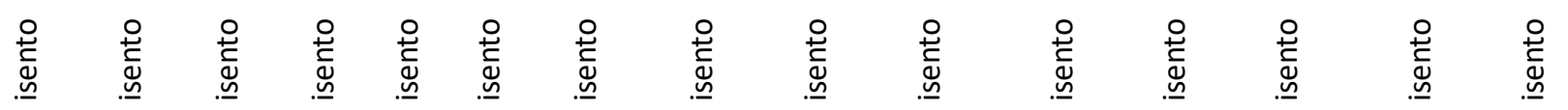

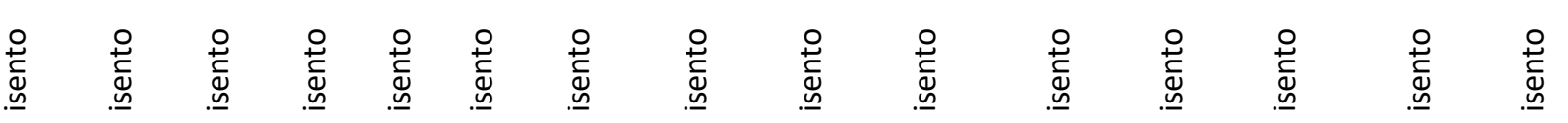

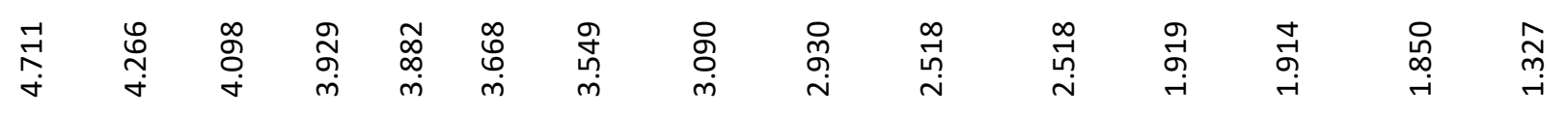

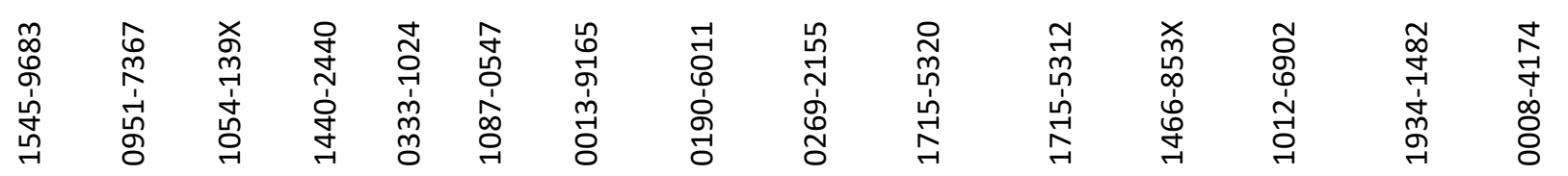

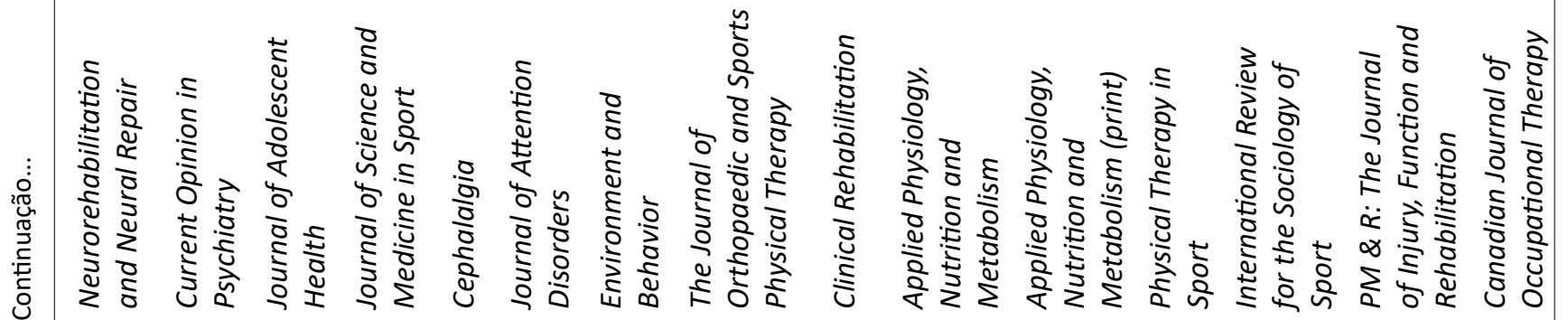




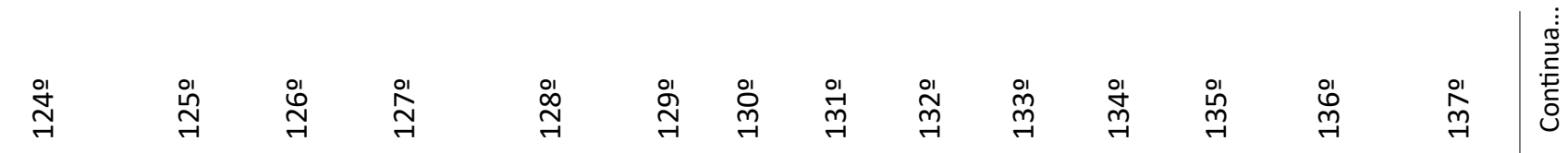

\begin{tabular}{|c|c|c|c|c|c|c|c|c|c|c|c|c|}
\hline 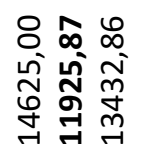 & 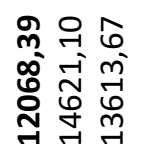 & 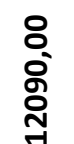 & 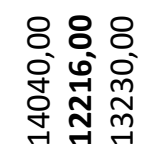 & 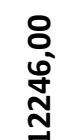 & 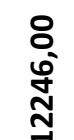 & 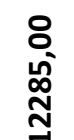 & 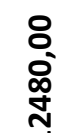 & 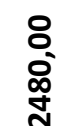 & & & & 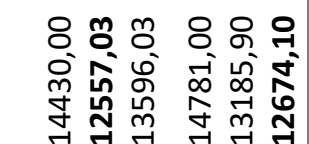 \\
\hline
\end{tabular}

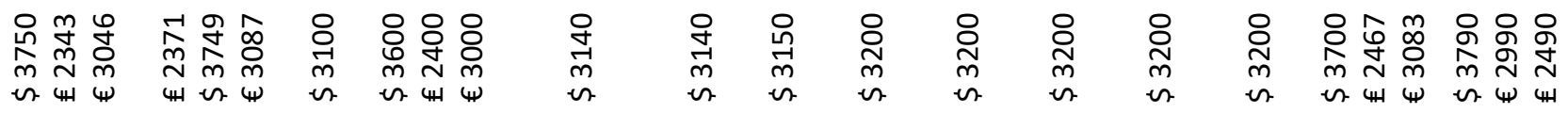

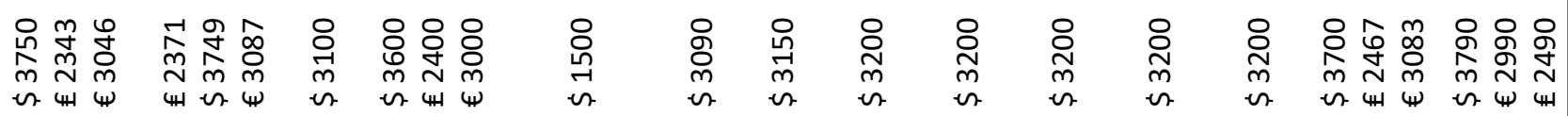

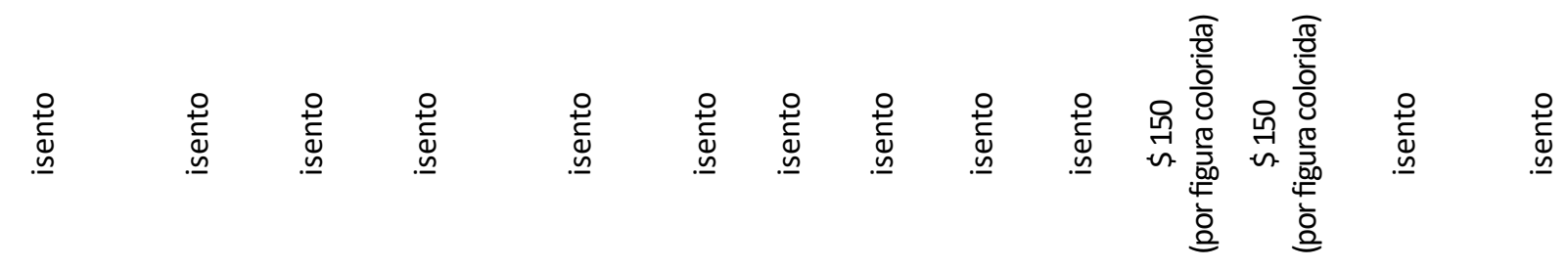

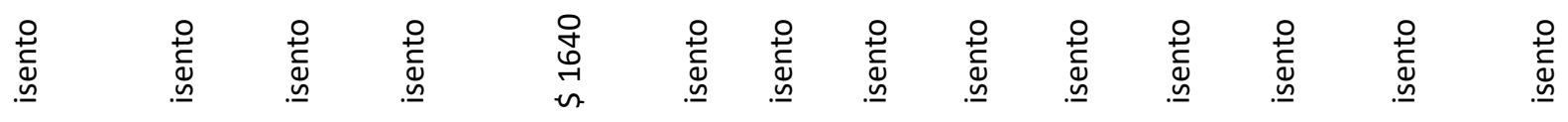

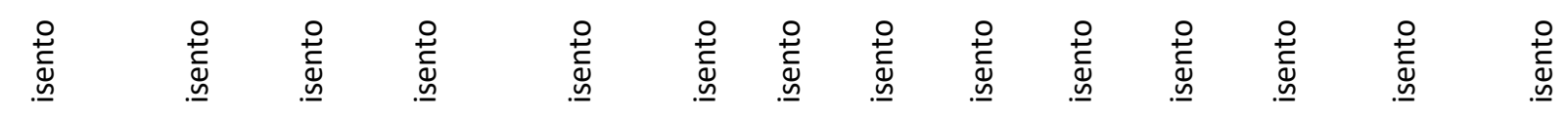

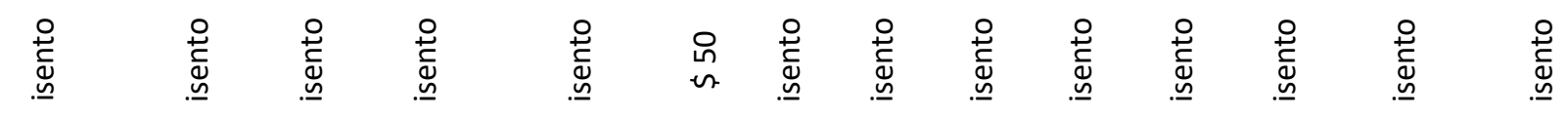

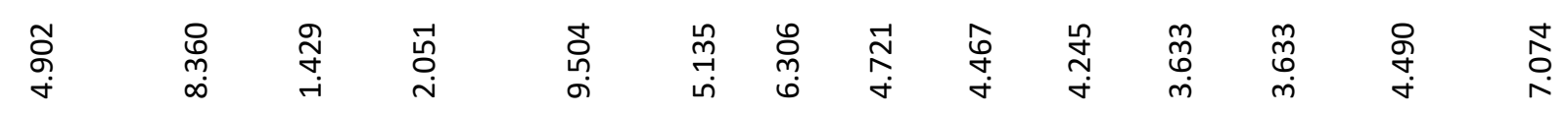

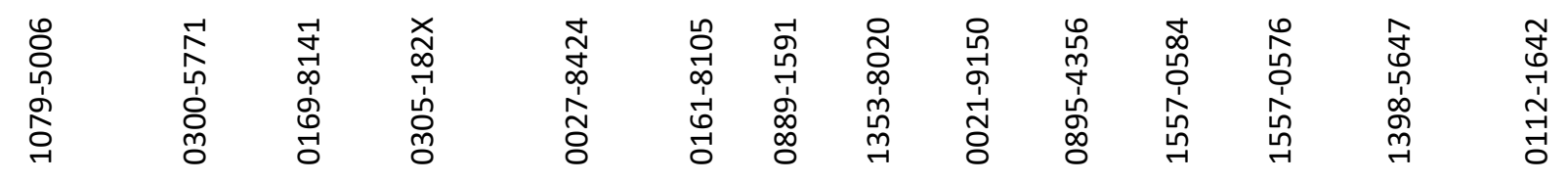

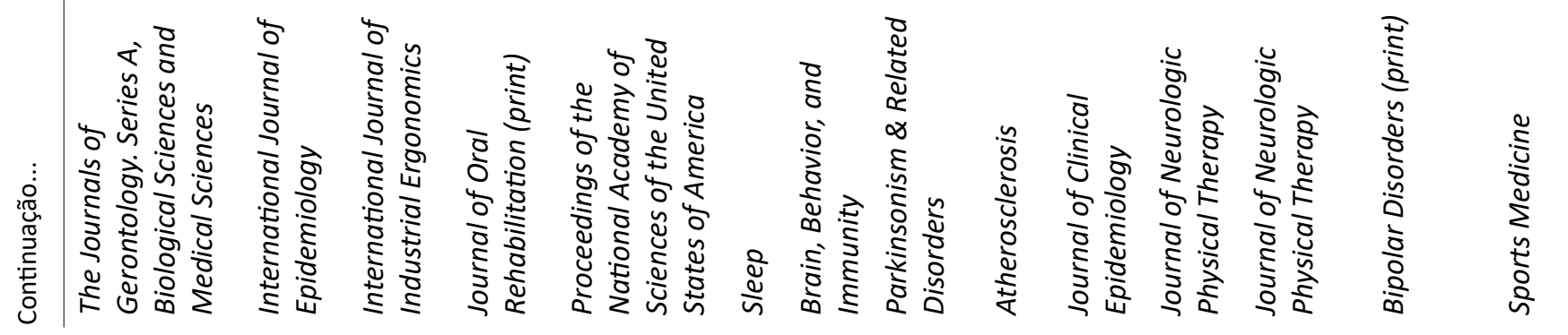




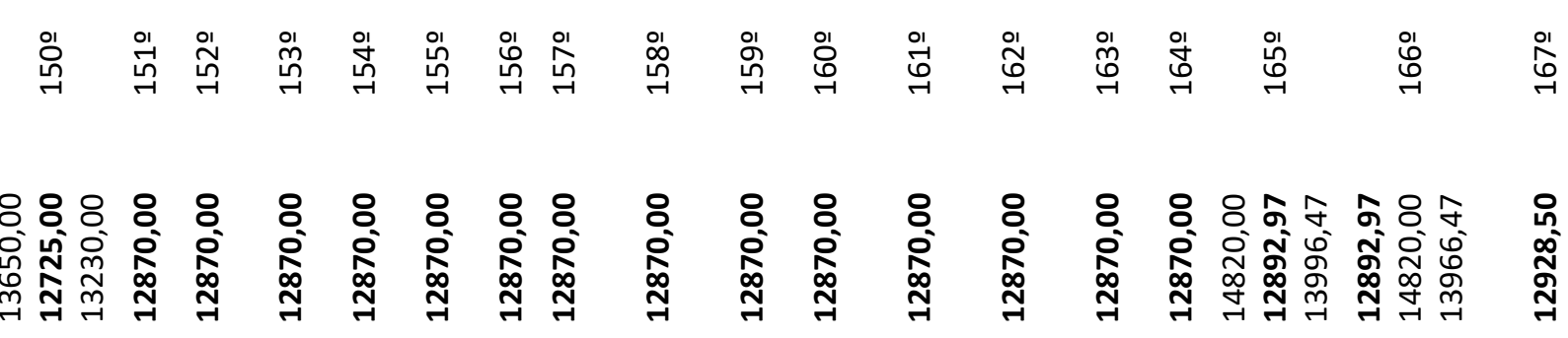

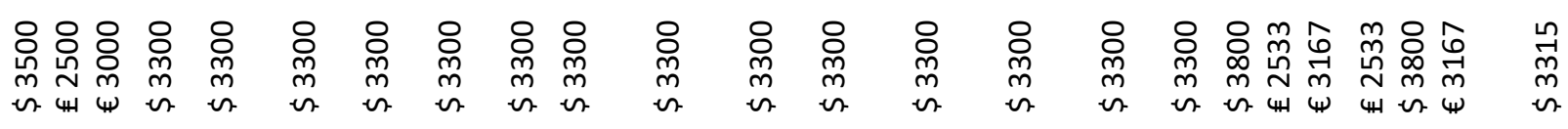

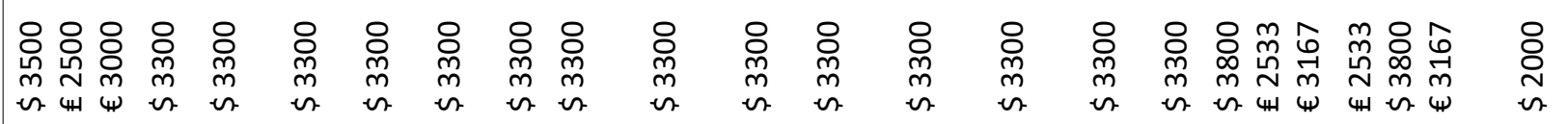

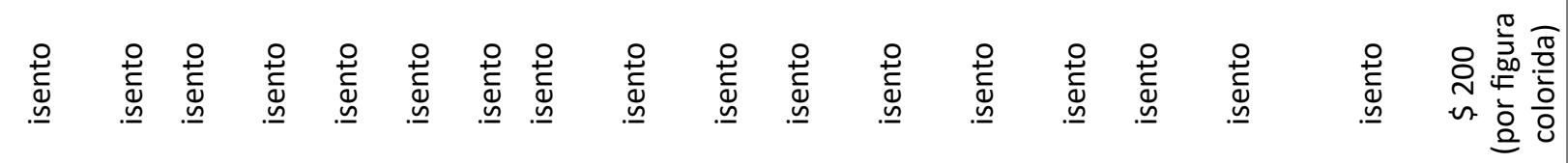

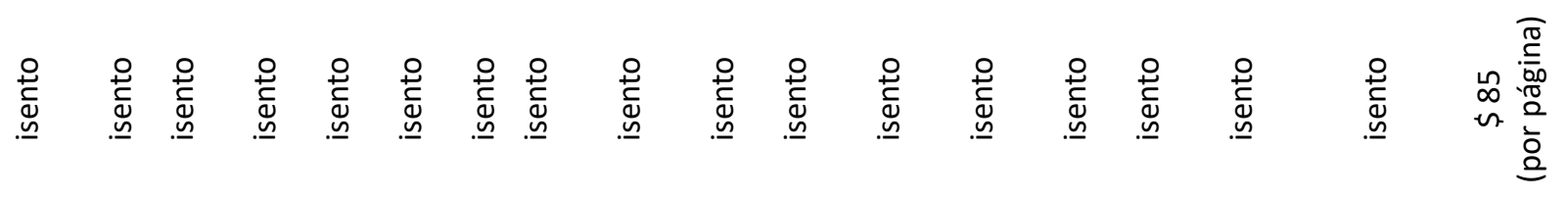

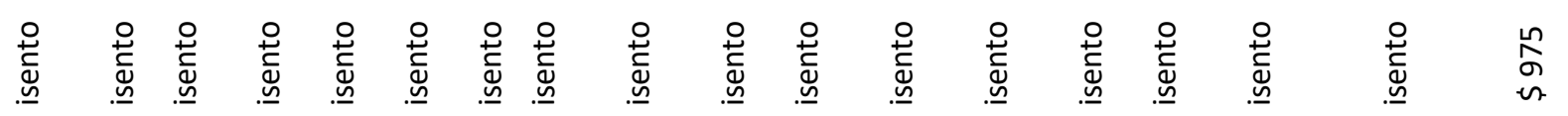

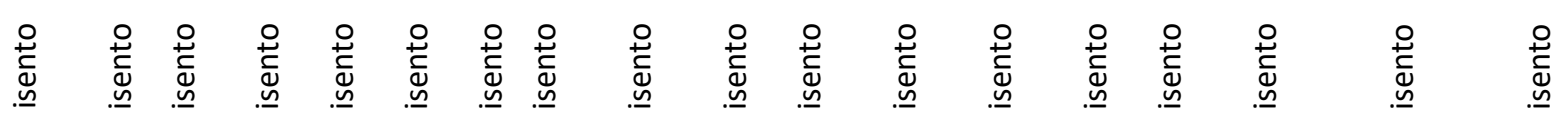

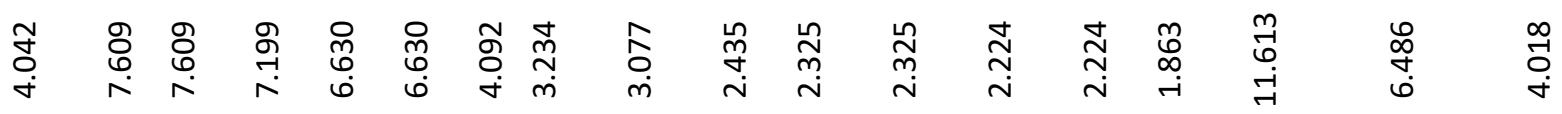

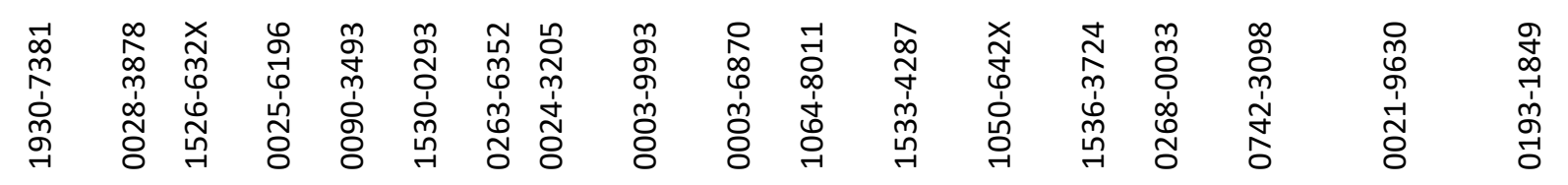

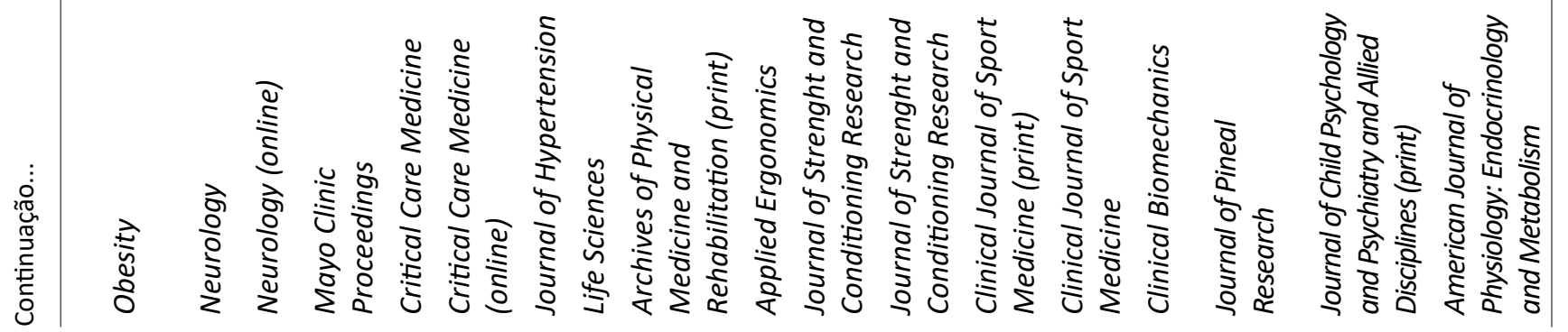




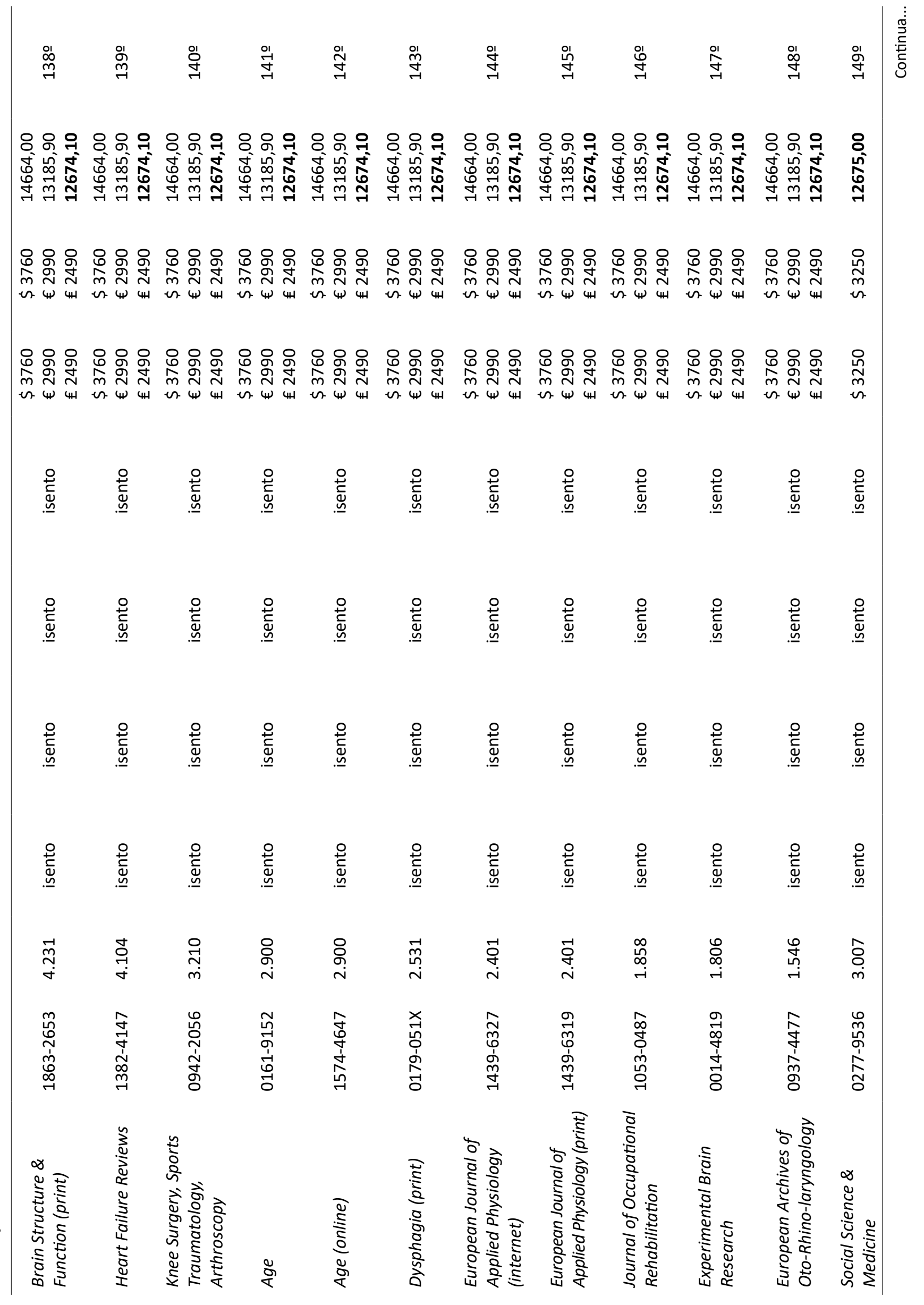


兽

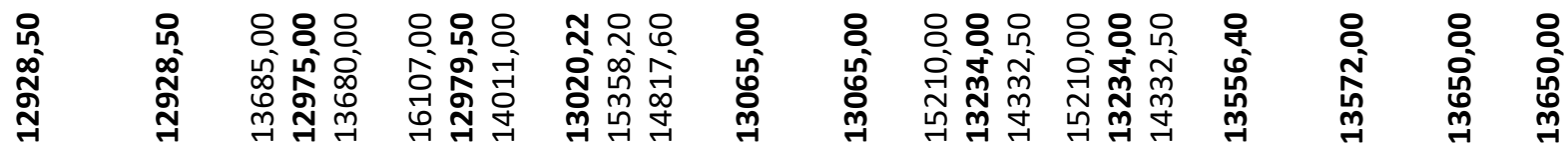

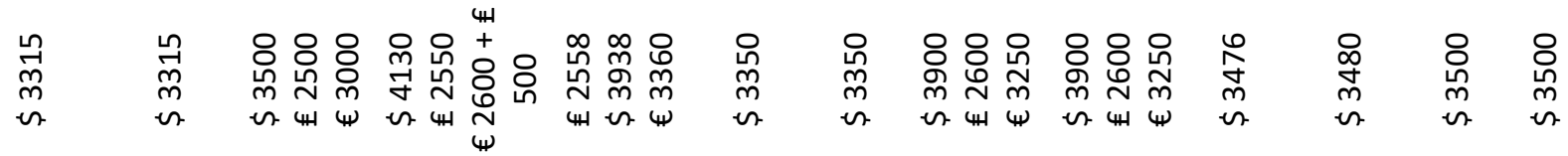

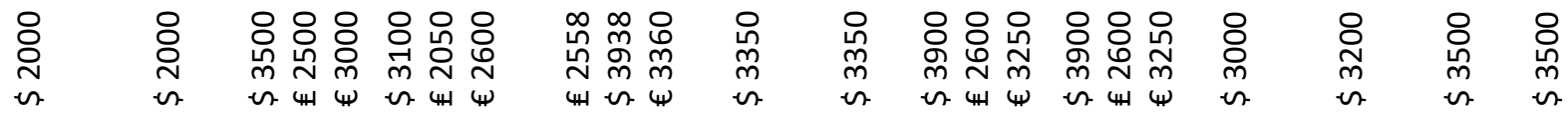

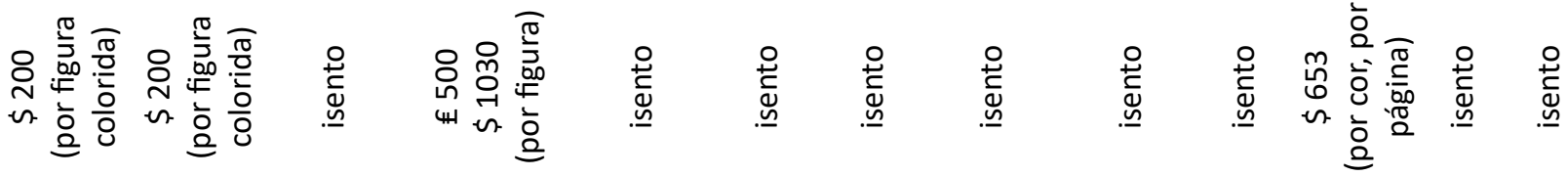

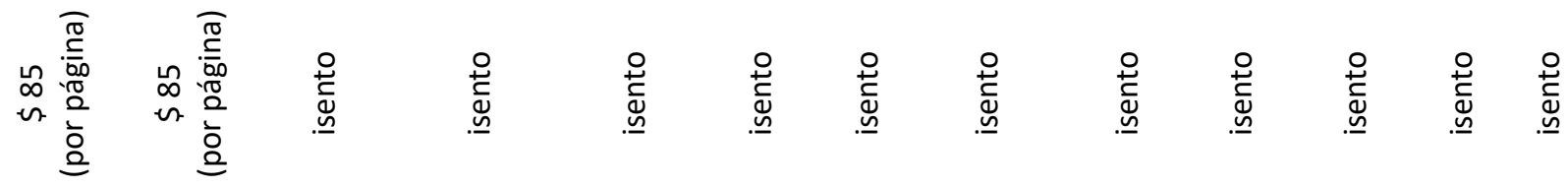

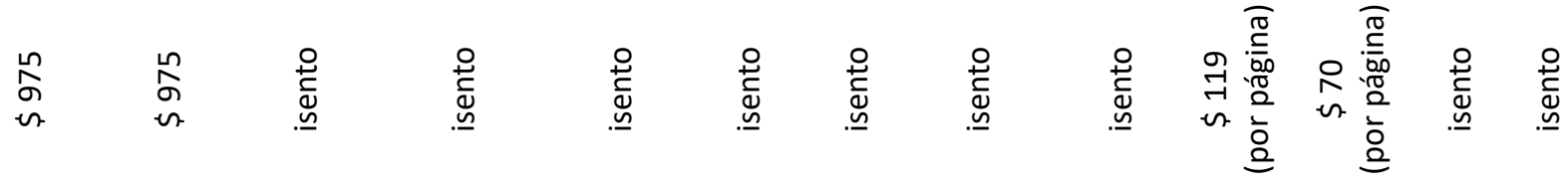

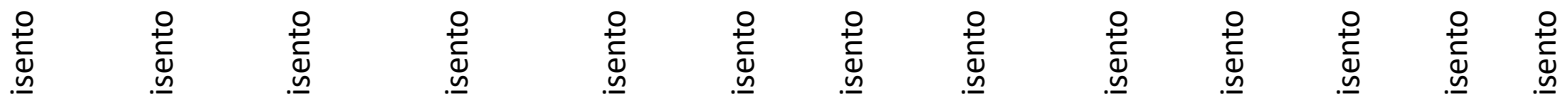

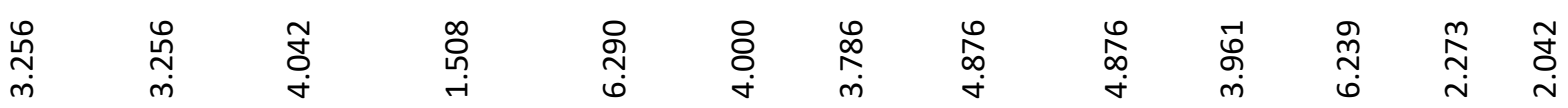

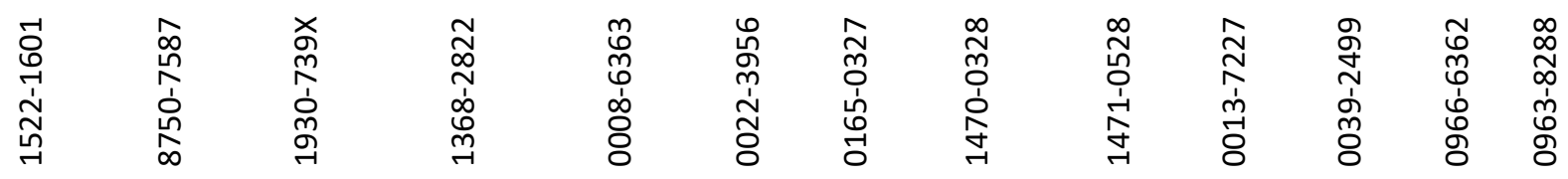

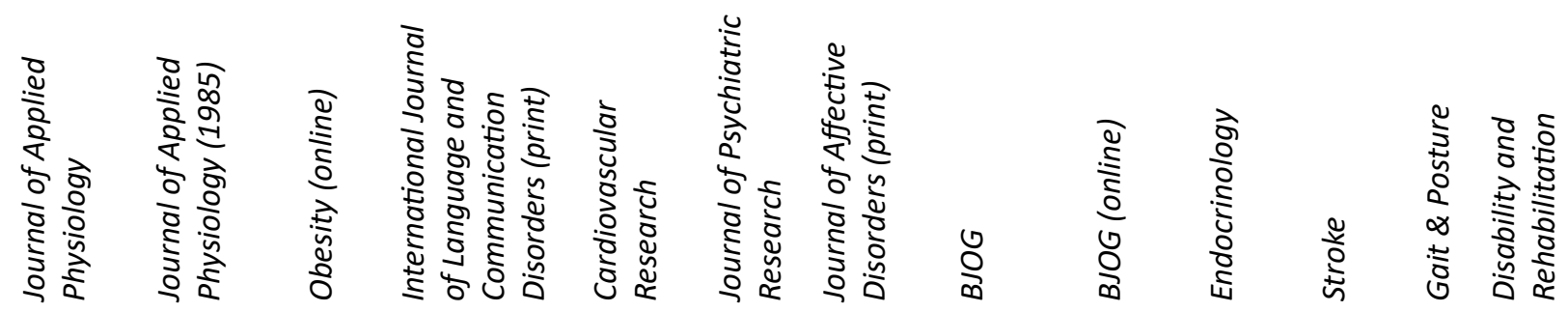




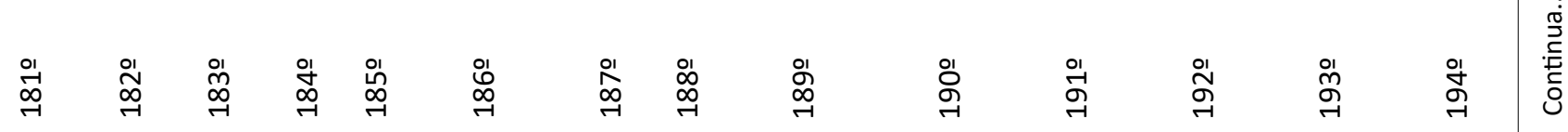

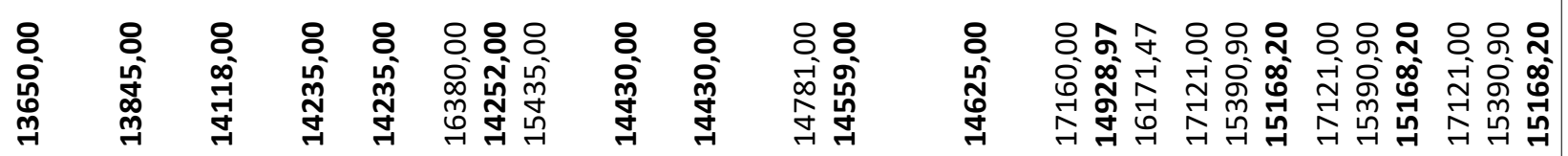

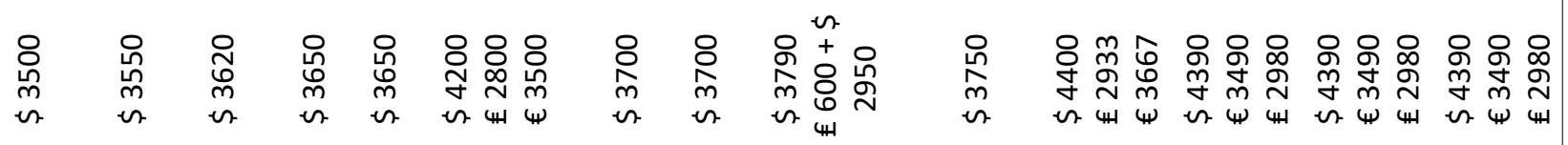

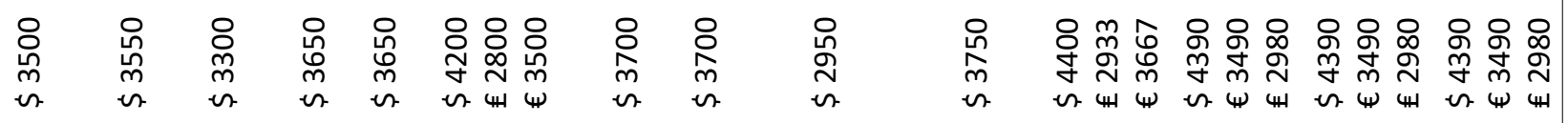

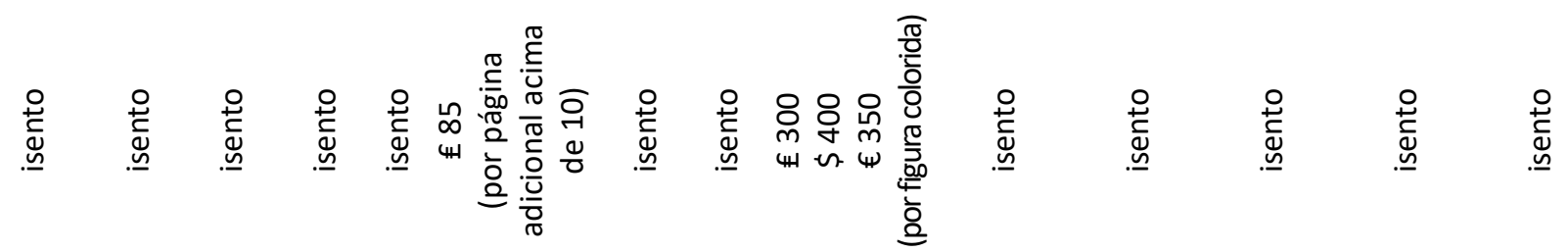

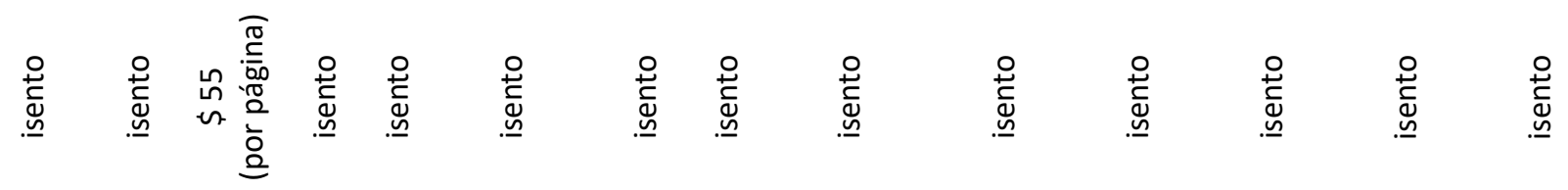

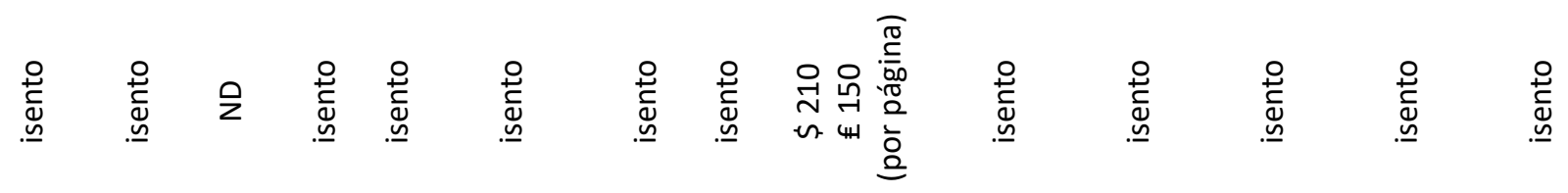

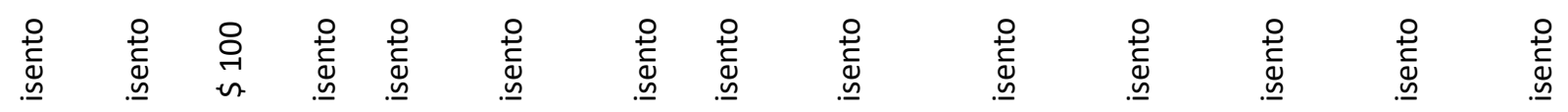

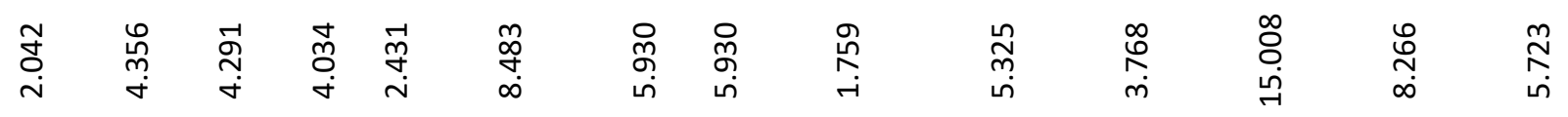

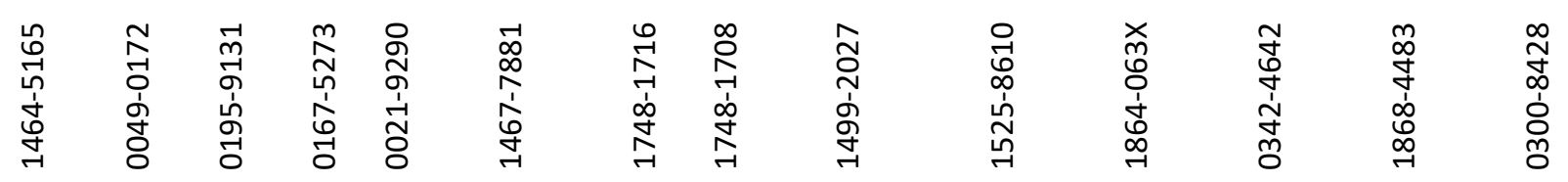

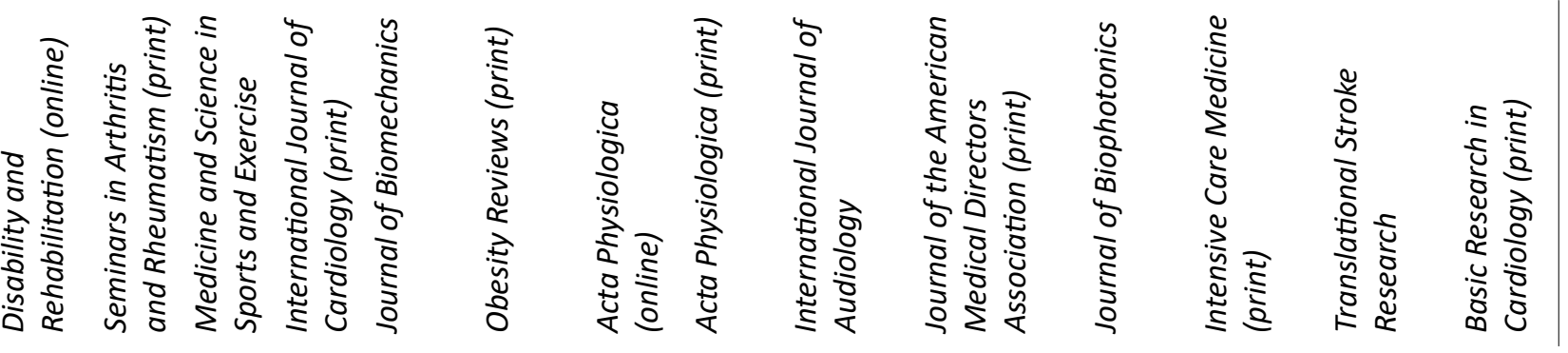




\begin{tabular}{|c|c|c|c|c|c|c|c|c|c|c|c|c|}
\hline 잉 & $\begin{array}{l}\text { ㅇํ } \\
\text { ه̆ }\end{array}$ & 品 & 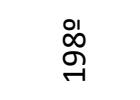 & 익 & ᄋ̊̀ & $\stackrel{\circ}{\stackrel{0}{0}}$ & 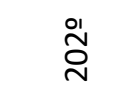 & 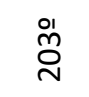 & ষ্ํํ & 筤 & 光 & $\stackrel{\circ}{\stackrel{\circ}{0}}$ \\
\hline $\begin{array}{l}8 \\
0 \\
\text { ज̃ } \\
\text { กิ }\end{array}$ & $\begin{array}{l}8 \\
\text { - } \\
\text { กิ } \\
\text { กิ }\end{array}$ & $\begin{array}{l}8 \\
\text { in } \\
\text { ơ } \\
\text { H }\end{array}$ & 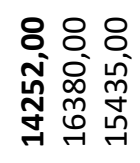 & $\begin{array}{l}\text { 8 } \\
\text { ¿ें } \\
\text { फ़ }\end{array}$ & 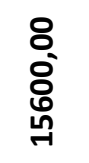 & 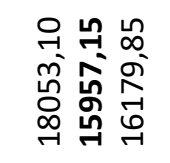 & 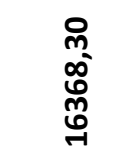 & $\begin{array}{l}8 \\
0 \\
0 \\
00 \\
0\end{array}$ & 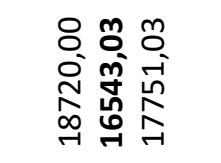 & 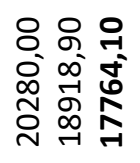 & 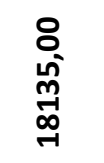 & 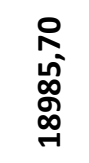 \\
\hline $\begin{array}{l}\text { ৪े } \\
\text { ले } \\
\text { v }\end{array}$ & $\begin{array}{l}\text { ০ } \\
\text { ल } \\
\text { n. }\end{array}$ & $\begin{array}{l}\text { 유 } \\
\text { مे } \\
\text { n. }\end{array}$ & 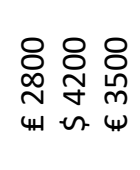 & $\begin{array}{l}\text { o } \\
\text { + } \\
\text { n. }\end{array}$ & $\begin{array}{l}\text { ò } \\
\text { + } \\
\text { n. }\end{array}$ & 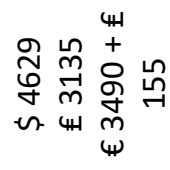 & $\begin{array}{l}\hat{\sigma} \\
\stackrel{+}{+} \\
\text { nt }\end{array}$ & 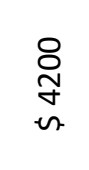 & 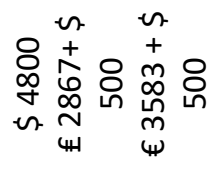 & 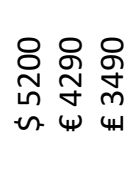 & 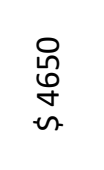 & $\underset{\substack{m \\
m}}{\stackrel{m}{m}}$ \\
\hline $\begin{array}{l}8 \\
\text { న్ } \\
\text { n. }\end{array}$ & $\begin{array}{l}8 \\
\substack{n \\
m \\
n}\end{array}$ & $\begin{array}{l}\text { 응 } \\
\text { m } \\
\text { n. }\end{array}$ & 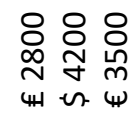 & $\begin{array}{l}8 \\
\text { o } \\
\text { w. }\end{array}$ & 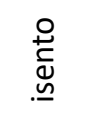 & 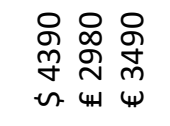 & 只 & $\begin{array}{l}\stackrel{0}{h} \\
\text { m } \\
n\end{array}$ & 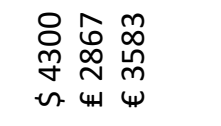 & 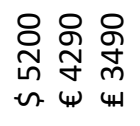 & \begin{tabular}{l}
0 \\
h్ \\
\multirow{0}{+}{} \\
w.
\end{tabular} & $\underset{\substack{\infty \\
m}}{m}$ \\
\hline 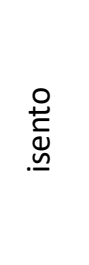 & 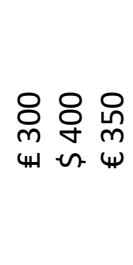 & 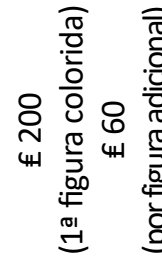 & $\begin{array}{l}\stackrel{0}{\tilde{v}} \\
\stackrel{\underline{w}}{\underline{\underline{m}}}\end{array}$ & $\begin{array}{l}\stackrel{0}{\tilde{v}} \\
\stackrel{\underline{w}}{\underline{\underline{n}}}\end{array}$ & 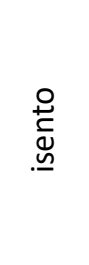 & 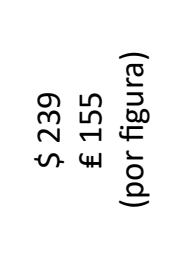 & 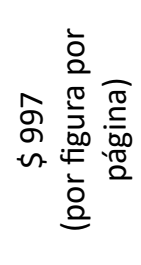 & 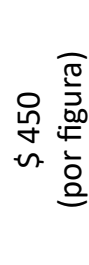 & 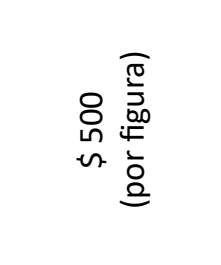 & $\begin{array}{l}\stackrel{0}{\tilde{v}} \\
\stackrel{\underline{w}}{\underline{\underline{n}}}\end{array}$ & $\begin{array}{l}\stackrel{0}{\tilde{v}} \\
\stackrel{\underline{w}}{\underline{\underline{n}}}\end{array}$ & 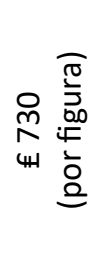 \\
\hline 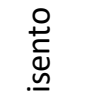 & 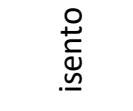 & $\begin{array}{l}\stackrel{0}{*} \\
\stackrel{\underline{W}}{\underline{\underline{n}}}\end{array}$ & 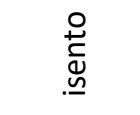 & $\begin{array}{l}\stackrel{0}{*} \\
\stackrel{0}{0} \\
. \underline{\underline{M}}\end{array}$ & $\begin{array}{l}\text { ò } \\
\text { q } \\
\text { n. }\end{array}$ & $\begin{array}{l}\stackrel{0}{ \pm} \\
\stackrel{0}{0} \\
. \underline{M}\end{array}$ & 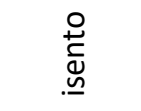 & $\begin{array}{l}\stackrel{0}{*} \\
\stackrel{0}{0} \\
. \underline{.1}\end{array}$ & 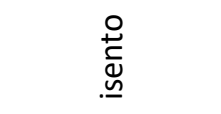 & $\begin{array}{l}\stackrel{0}{*} \\
\stackrel{0}{ \pm} \\
. \underline{\underline{N}}\end{array}$ & $\begin{array}{l}\stackrel{0}{0} \\
\stackrel{0}{0} \\
. \underline{M}\end{array}$ & $\begin{array}{l}\stackrel{0}{*} \\
\stackrel{0}{0} \\
. \underline{\underline{N}}\end{array}$ \\
\hline $\begin{array}{l}\stackrel{0}{\vec{\nu}} \\
\text { } \\
. \underline{n}\end{array}$ & $\begin{array}{l}\stackrel{0}{\vec{d}} \\
\stackrel{\tilde{d}}{.}\end{array}$ & $\begin{array}{l}\stackrel{0}{\vec{d}} \\
\stackrel{\tilde{d}}{.}\end{array}$ & $\begin{array}{l}\stackrel{0}{\vec{\nu}} \\
\stackrel{\tilde{d}}{.}\end{array}$ & $\begin{array}{l}\stackrel{0}{\vec{d}} \\
\stackrel{\underline{d}}{.}\end{array}$ & $\begin{array}{l}\stackrel{0}{ \pm} \\
\text { } \\
. \underline{n}\end{array}$ & $\begin{array}{l}\stackrel{0}{\vec{\nu}} \\
\stackrel{\sim}{\underline{n}}\end{array}$ & $\begin{array}{l}\text { Oे } \\
\text { m } \\
\text { n. }\end{array}$ & 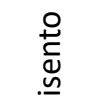 & 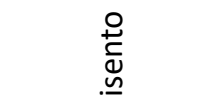 & $\begin{array}{l}\stackrel{0}{\tilde{d}} \\
\stackrel{\underline{d}}{.}\end{array}$ & 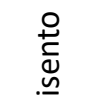 & 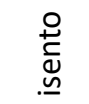 \\
\hline $\begin{array}{l}\stackrel{0}{\tilde{v}} \\
\stackrel{\underline{m}}{\underline{\underline{n}}}\end{array}$ & $\begin{array}{l}\stackrel{0}{\tilde{v}} \\
\stackrel{\underline{d}}{\underline{\underline{n}}}\end{array}$ & $\begin{array}{l}\stackrel{0}{\bar{v}} \\
\stackrel{\underline{v}}{.}\end{array}$ & $\begin{array}{l}\stackrel{0}{\tilde{v}} \\
\stackrel{\underline{v}}{.}\end{array}$ & $\begin{array}{l}\stackrel{0}{\tilde{v}} \\
\stackrel{\underline{d}}{\underline{\underline{n}}}\end{array}$ & $\begin{array}{l}\stackrel{0}{\mathrm{v}} \\
\stackrel{d}{\underline{m}}\end{array}$ & $\begin{array}{l}\stackrel{0}{\tilde{v}} \\
\stackrel{\underline{m}}{\underline{\underline{n}}}\end{array}$ & $\begin{array}{l}\stackrel{0}{\tilde{v}} \\
\stackrel{\underline{d}}{\underline{\underline{n}}}\end{array}$ & 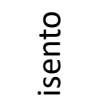 & $\begin{array}{l}\stackrel{0}{\tilde{v}} \\
\stackrel{\underline{m}}{\underline{\underline{n}}}\end{array}$ & 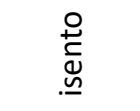 & 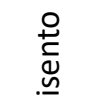 & 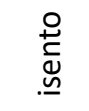 \\
\hline 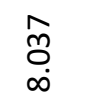 & $\underset{i}{\stackrel{-}{r}}$ & 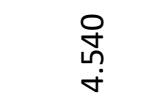 & 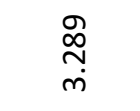 & 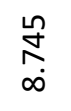 & $\begin{array}{l}\hat{0} \\
0\end{array}$ & $\begin{array}{l}\text { Hี } \\
\text { ம் }\end{array}$ & $\begin{array}{l}\stackrel{+}{0} \\
\stackrel{\sim}{\text { i }}\end{array}$ & $\begin{array}{l}\hat{\emptyset} \\
\ddot{n}\end{array}$ & 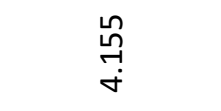 & 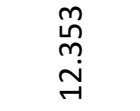 & $\stackrel{\vec{n}}{\stackrel{-}{n}}$ & $\begin{array}{l}\tilde{O} \\
\stackrel{+}{+}\end{array}$ \\
\hline 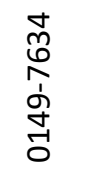 & 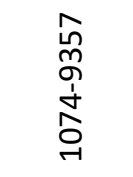 & $\begin{array}{l}\underset{n}{N} \\
\text { ñ } \\
\stackrel{\sim}{8}\end{array}$ & 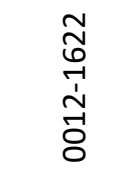 & 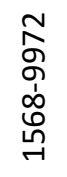 & 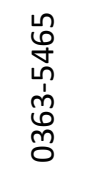 & 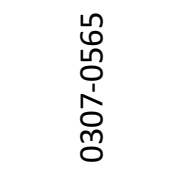 & 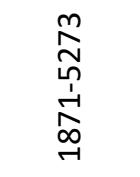 & 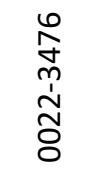 & 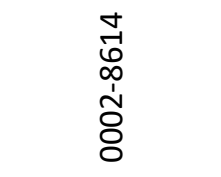 & $\begin{array}{l}\underset{N}{N} \\
\stackrel{-}{1} \\
\stackrel{+}{+} \\
\stackrel{N}{N}\end{array}$ & 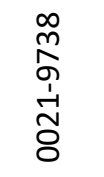 & 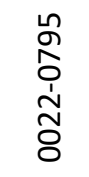 \\
\hline 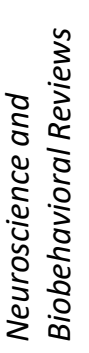 & 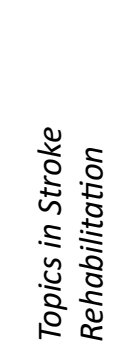 & 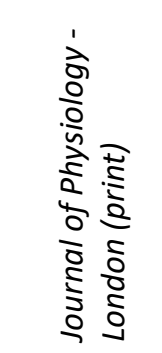 & 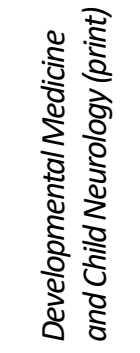 & 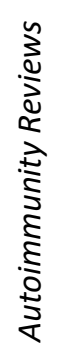 & 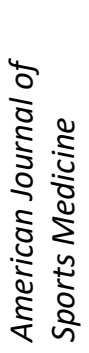 & 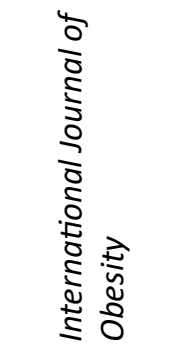 & 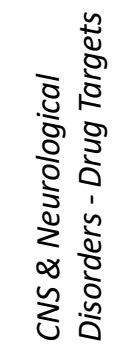 & 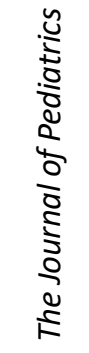 & 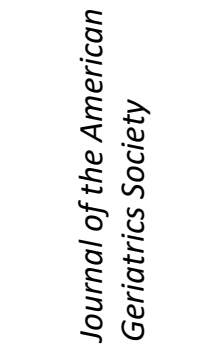 & 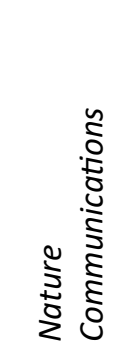 & 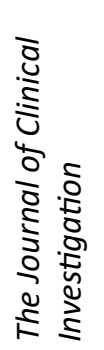 & 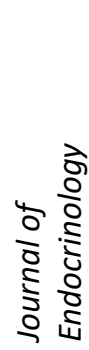 \\
\hline
\end{tabular}




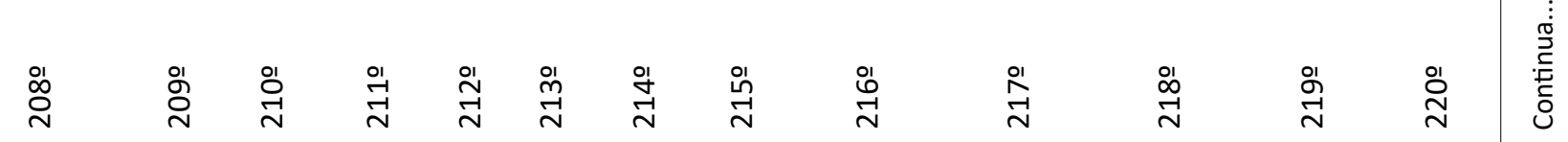

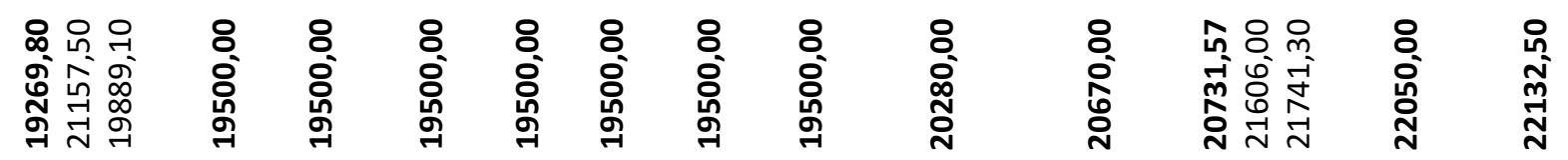

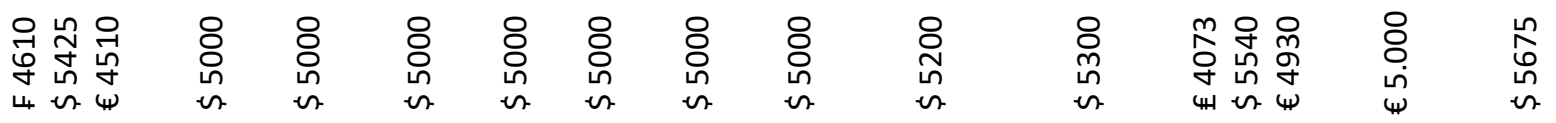

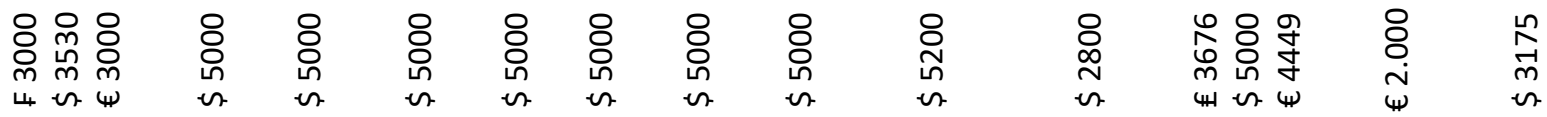

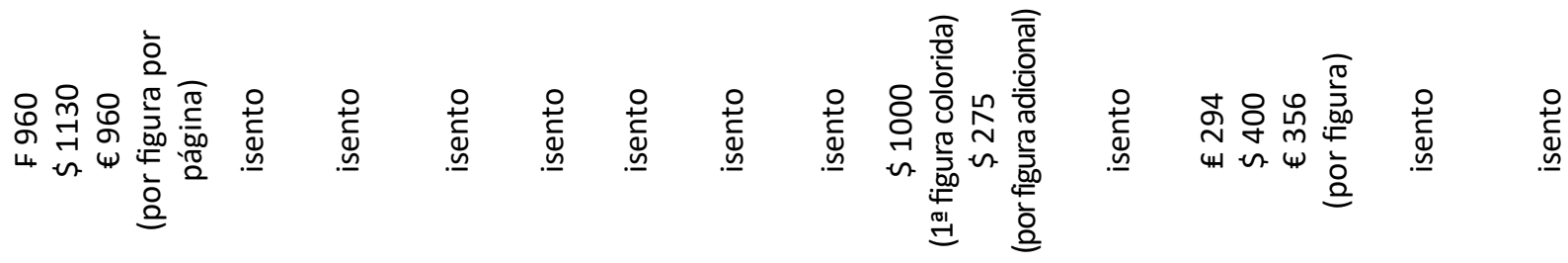

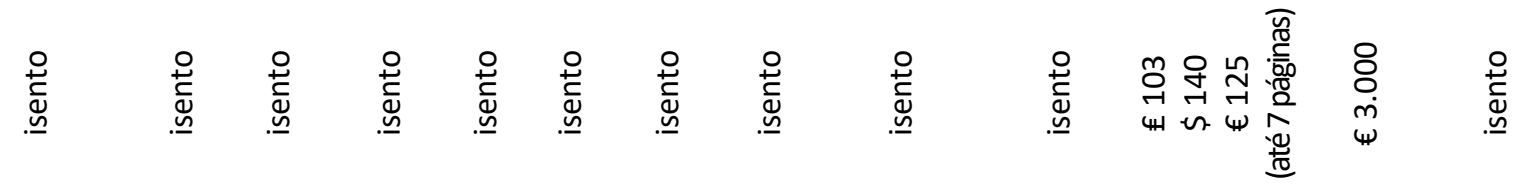

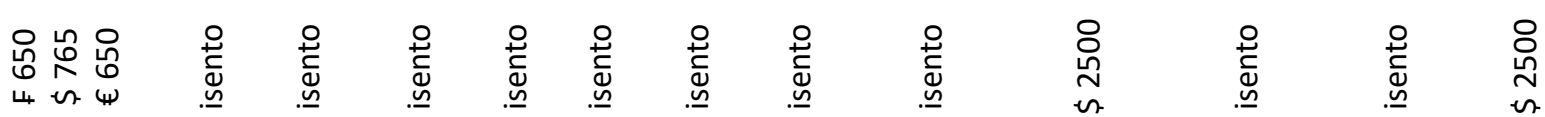

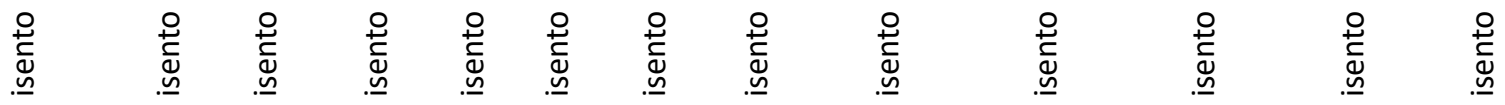

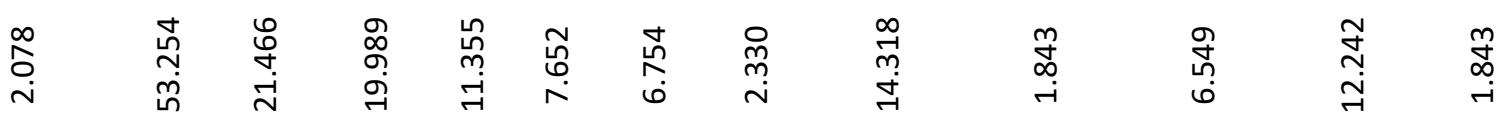

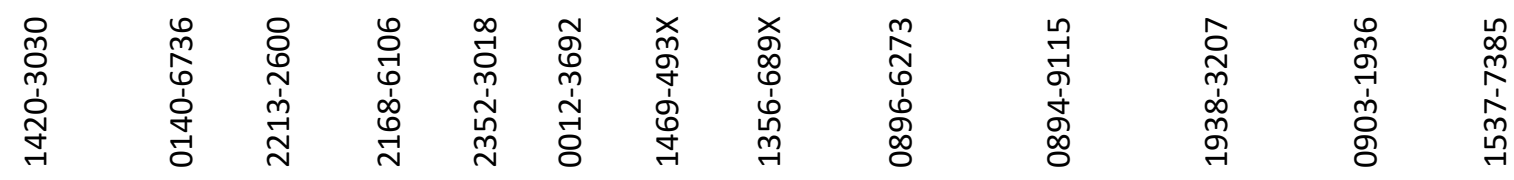

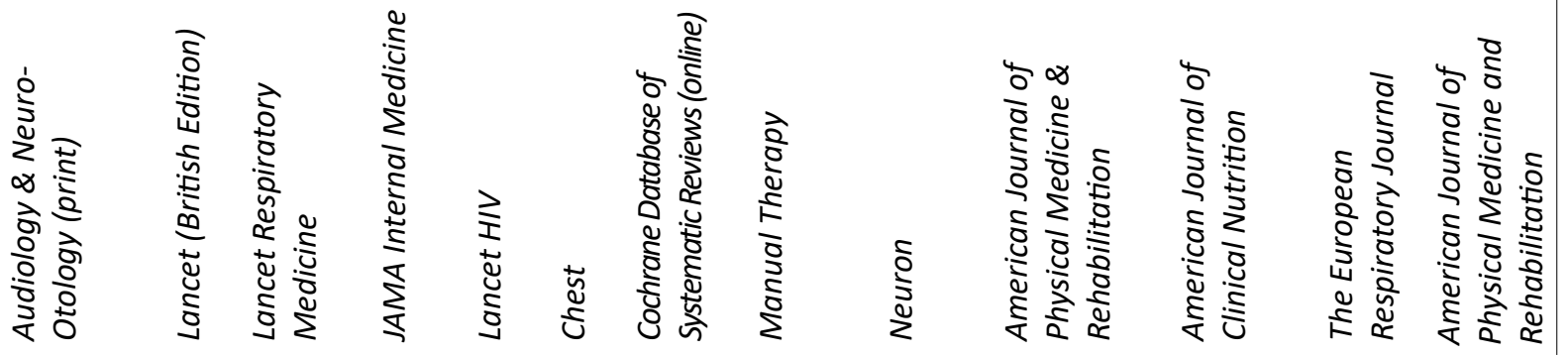




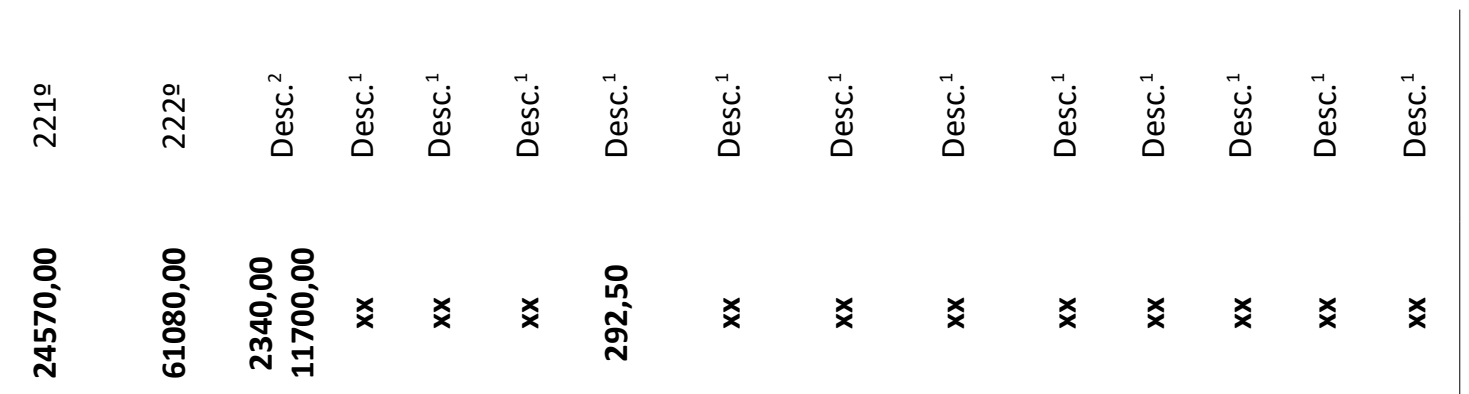

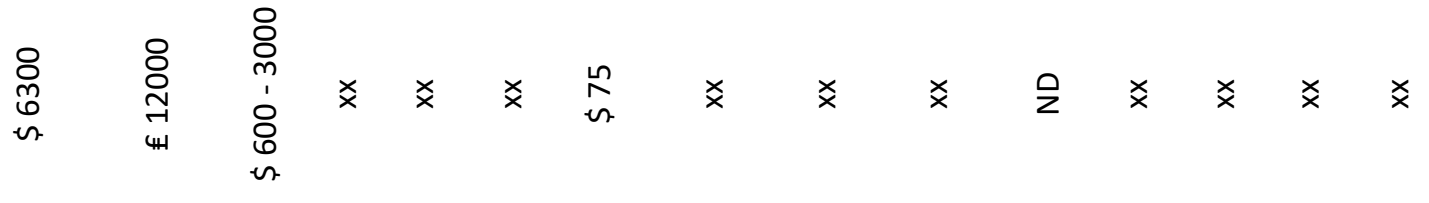

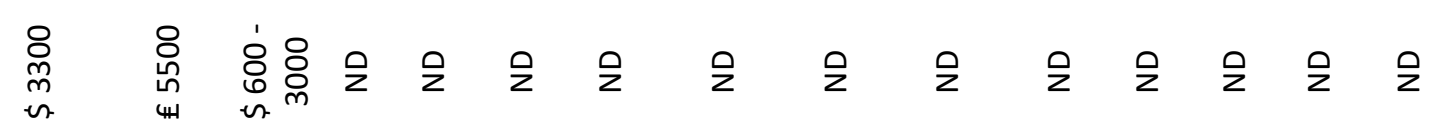

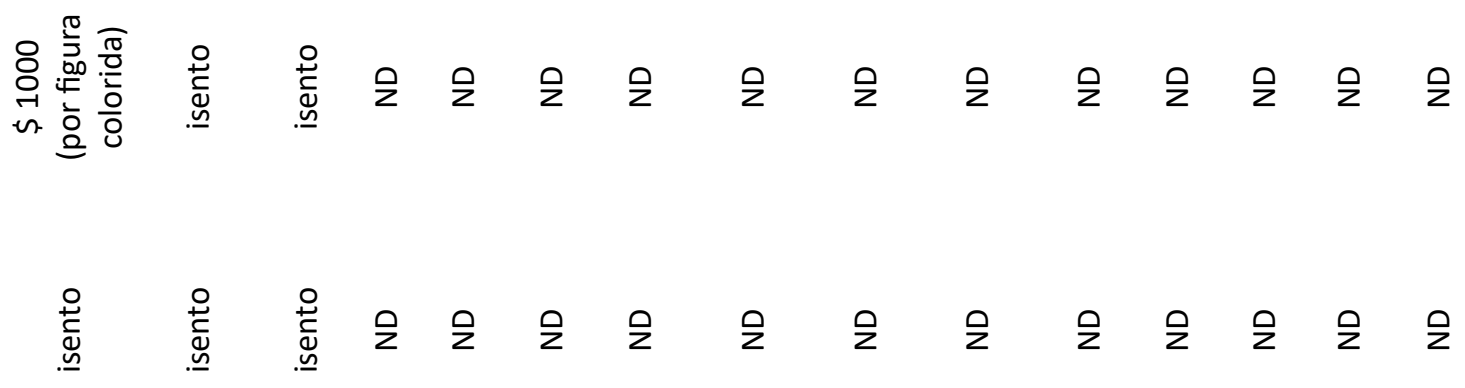

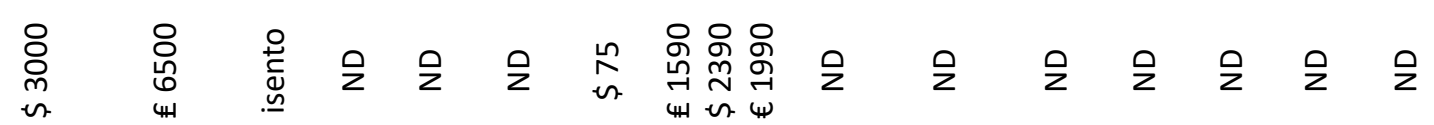

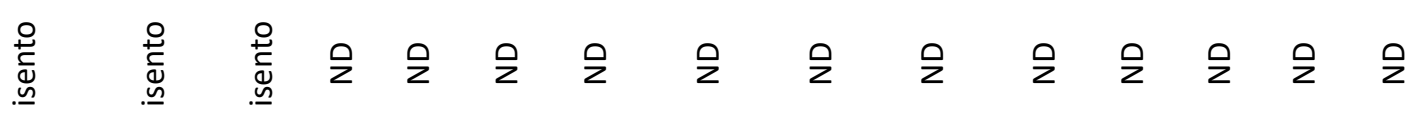

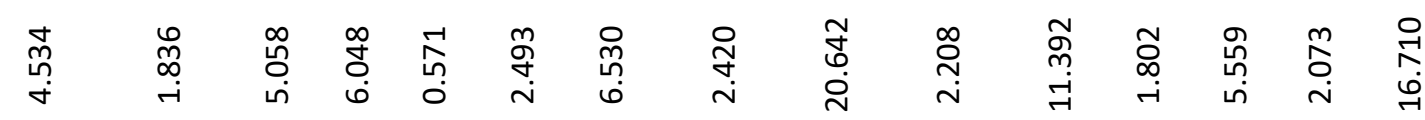

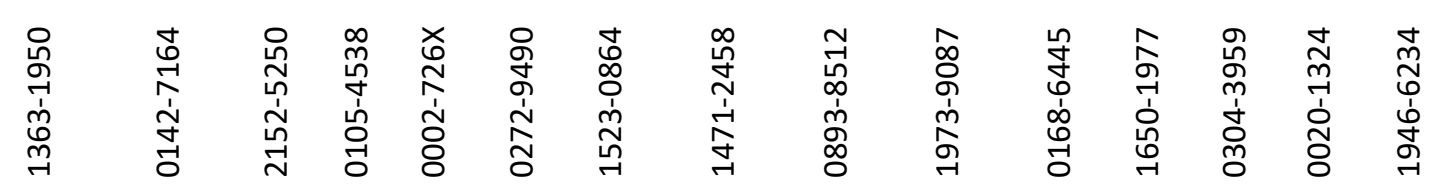
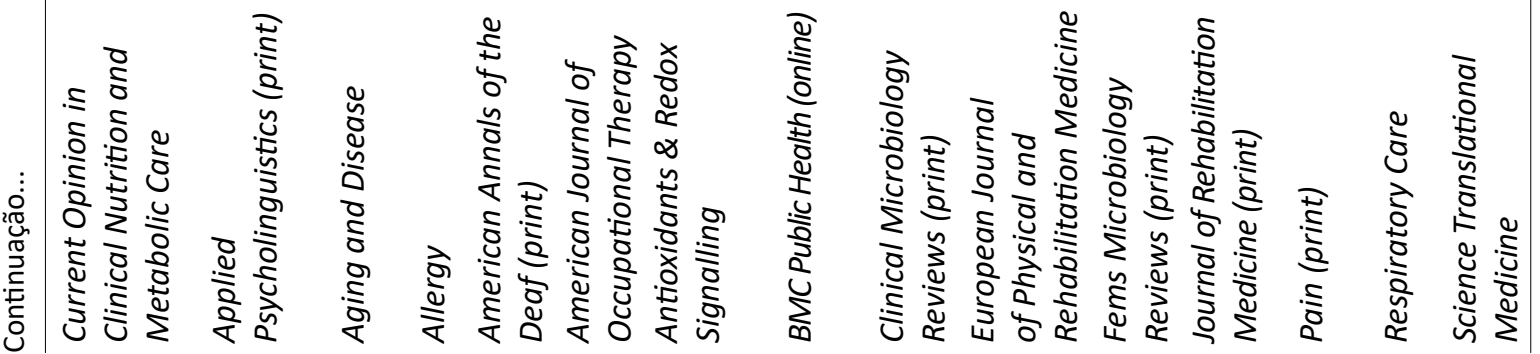

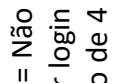

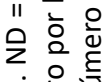

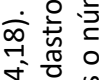

ㄴ.

4 造

in 든

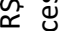

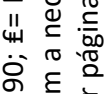

mi

光. 迩焉

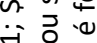

鸟岛

थै के

品 $\frac{0}{3}$

균

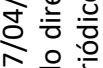

응 :웧

윰응 은

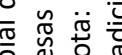

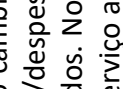

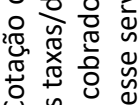

U.

空

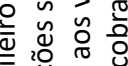

ॠٓ⿺辶ّ

बळ.

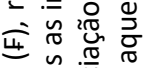

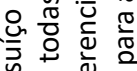

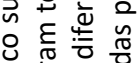

政

을

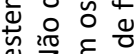

$\pi=\frac{\pi}{20} 20$

空芯悹

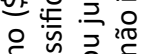

은 $\frac{\pi}{4}$ ह $\frac{\pi}{0}$

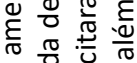

范

응 룽

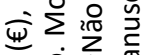

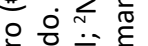

卷 䨌

i⿱ उ 